\title{
LIFETIME INEQUALITY MEASURES FOR AN EMERGING ECONOMY: THE CASE OF CHILE
}

\author{
MAURICIO M. TEJADA \\ (ILADES - UNIVERSIDAD ALBERTO HURTADO)
}

\begin{abstract}
Cross-section and lifetime measures of inequality are different. While the latter reflects long run resources available to individuals, the former does not. This emphasizes the dynamic dimension of inequality. Many studies have analyzed and compared economies using this lifetime perspective, however, they all focus on the United States, Canada or Europe. Since the literature is scarce for emerging economies, this paper seeks to fill this gap focusing on the analysis of lifetime inequality for an emerging economy using a search-theoretic framework. The model, which is structurally estimated with Chilean data, uses career simulations to construct lifetime measures of inequality. A set of experiments are also performed to isolate the mobility and distribution effects on inequality, the marginal effect on inequality of individual parameters, and the importance of the different ages. Results indicate that inequality is not only high in a cross-section perspective, but also in a lifetime perspective. Low mobility is the main source of lifetime inequality in the Chilean labor market being the older workers who experience the lowest degree of mobility. Finally, regulation of the labor market is important because it affects the degree of mobility in the labor market.
\end{abstract}

JEL Classification: C51, D63, J40, J64

Key Words: search models, on-the-job search, maximum likelihood estimation, inequality, lifetime welfare.

\section{INTRODUCTION}

Cross-section and lifetime measures of inequality are different, because the latter reflects long run resources available to individuals while the former does not. Moreover, cross-section distributions of earnings are just snapshots of the workforce (Gottschalk and Moffitt, 1994). Therefore, the use of current income to perform inequality studies can be misleading due to the existence of a transitory component in the current income (Blundell and Preston, 1998; Krueger and Perri, 2006). This emphasizes the dynamic dimension of

Date: November, 2013.

The author is grateful to Luca Flabbi, James Albrecht, and Susan Vroman for their valuable advice and suggestions. He would also like to thank Christopher Flinn, Guido Menzio and Gianluca Violante for their useful and constructive comments. Lastly, he would like to thank the "Subsecretaría de Previsión Social" of Chile for providing the databases of the Job Market Histories and Social Security Surveys. All the results are the author's responsibility and in no way compromise the Government of Chile. E-mail: matejada@uahurtado.cl. 
inequality. Along these lines, Flabbi and Leonardi (2010) indicate that earnings inequality is not simply described by the current earnings but also by mobility across jobs and labor market states. Therefore, lifetime inequality measures should take into account labor market states and lifetime wage profiles. Buchinsky and Hunt (1999) and Bowlus and Robin (2004) complement this idea suggesting that individual welfare not only depends on the current employment position but also on the expected evolution of this position over time.

Many studies have analyzed and compared economies using this lifetime perspective, however, they all focus on the United States, Canada or Europe. In the case of emerging economies, the literature is scarce, perhaps because of data limitations. These economies also have the particularity that in general they have relatively more regulated labor markets and high cross-sectional measures of inequality as can be seen in figure 1 . This paper seeks to fill this gap and its focus is on the analysis of wage inequality using the lifetime perspective for an emerging economy. In doing so, some additional evidence on the link between labor market regulation and low wage flexibility and mobility is provided. This paper focuses on the Chilean labor market for two reasons: first, Chile is one of the countries with the highest cross-sectional (and most persistent) income inequality, not only in Latin America but also worldwide; and second, Chile has a rich dataset with labor market histories. There are many inequality studies for the case of Chile but almost all of them use a cross-section distribution of earnings in analyzing inequality. Therefore, this paper contributes to improving the standard empirical measures of inequality for Chile providing lifetime measures of inequality.

This paper uses a search-theoretic framework to analyze long run inequality through the lens of the labor market. In analyzing income inequality, the job market outcomes play a key role (see figure 2$)^{1}$. In particular, using the Social Protection Survey dataset for Chile, a structural search model with on-the-job search is estimated and simulations of careers are used to construct lifetime measures of inequality. The lifetime welfare is then measured as the sum of the discounted values of the simulated labor incomes (Flinn, 2002; Flabbi and Leonardi, 2010). The estimation controls for (observed) heterogeneity in education assuming segmented markets for skilled and unskilled workers. As is usual in the estimation of this type of models, two issues emerge: the first is the right censoring problem and the second is the so called Initial Conditions Problem (Flinn, 2002). Both problems are controlled in the estimation. Finally, the model is used to perform three experiments to isolate the mobility and distribution effects on inequality and to find differences in the labor market dynamics by age. These experiments are done comparing the Chilean labor market with a benchmark economy that has a more flexible labor market (the United States); calculating

\footnotetext{
${ }^{1}$ This figure also indicates that Chile has the highest level of inequality in the OECD countries (Chile became an OECD member on 7 May 2010)
} 
the marginal effects of the model parameters on lifetime inequality; and estimating mobility differentials by age.

Results indicate that inequality is not only high in a cross-sectional perspective, but also in a lifetime perspective and that the regulation of the labor market, reflected in the estimated parameters of the model, matters and has an impact on the degree of mobility in the labor market. This, in turn, has an impact on lifetime measures of inequality: a more flexible labor market generates a less unequal lifetime earnings distribution. This holds regardless of the skill level. Finally, the labor market is more mobile and comparatively less unequal for younger worker.

The paper is organized as follows. Section 2 briefly summarizes the related literature. Section 3 describes the model and its equilibrium. Section 4 describes the data and presents the likelihood function. Section 5 discusses the results of the estimation and the lifetime inequality measures. Section 6 presents a lifetime inequality decomposition, the marginal

effect of the estimated parameters in the lifetime inequality measure and an analysis of the labor market mobility by age. Finally, section 7 concludes.

\section{Related Literature}

This paper is closely related to the literature on structural estimation of partial equilibrium search models. The two closest articles are Flinn and Heckman (1982) and Flinn (2002). The former was the first to present a method to estimate this type of model and the latter extends that procedure to estimate models with on-the-job search.

The second group of related literature analyzes long-run welfare inequality and has two streams. The first is the study of income or earnings dynamics directly, in which some ARMA-type processes (or more complicated processes) are fitted to longitudinal earnings data to decompose earnings in its transitory and permanent components. Some examples are Gottschalk and Moffitt (1994) and Moffitt and Gottschalk (2002) for the United States, Gangl (2005) who compares Europe and the United States, Chen (2009) who uses data for Canada, the United States, United Kingdom and Germany, Bonhomme and Robin (2009) who use data on France, and Lilla and Staffolani (2009) for the Italian labor market. As was mentioned in the previous section, this literature is highly concentrated on the United States, United Kingdom, Canada and European Countries. For the case of Chile there is one paper, Huneeus and Repetto (2005), who analyze the dynamics of earnings in the life cycle (in line with for example Low et al., 2010) and it is the closest in spirit to this paper. They find that earnings are highly persistent, and therefore, there is little mobility of individuals across the distribution.

The second stream, which is the closest in terms of the approach used in this paper, is based on the search-theoretic framework and analyzes long-run inequality through the lens 
of the labor market (estimating a structural search model). This literature started with Flinn (2002) comparing the United States and Italy and continued with Bowlus and Robin (2004), who estimate a non-stationary search model for the United States, Flabbi and Mabli (2010), who estimate a model of household search for the United States, and finally, Flabbi and Leonardi (2010), who compare earnings distribution across time in the United States. It is important to mention that Postel-Vinay and Turon (2010) provide a link between these two steams of the literature analyzing the relationship between the dynamics of the labor market with search frictions and the dynamics of the earning process.

Finally, the third group of related literature analyzes inequality in Chile. The literature in this area is vast but practically all of the papers have used cross-section distribution of earnings in analyzing inequality. Some examples are: Beyer (1995), Beyer (1997), Contreras (1996), Cowan and De Gregorio (1996), Contreras (2002), Bravo and Marinovic (1997) and Larrañaga (2009). The main conclusions of this literature are: First, Chile is one of the countries with the highest cross-section income inequality worldwide; second, cross-section income inequality has been high and persistent across time (particularly in the nineties); and finally, the main factor in explaining between group cross-section income inequality is education. Recently, Sapelli (2011) has found that even though earnings inequality has been high and persistent overall, positive changes have been observed for young individuals.

\section{THe Model}

This section briefly describes the model setup and its solution. The model used in this paper to simulate the dynamics of the Chilean labor market is a standard partial equilibrium random search model with on-the-job search in the line of Flinn (2002). It is assumed that the environment is stationary and that the economy is populated by a continuum of infinitely lived risk neutral ${ }^{2}$ homogeneous agents. At each point in time agents can be unemployed and searching for a job ${ }^{3}$ or employed but looking for new job opportunities. While unemployed, agents receive an instantaneous utility, or possibly disutility, $b$ (interpreted as the value of leisure) and job offers which arrive according to a Poisson process with parameter $\lambda_{U}$. Job offers take the form of a wage $(w)$ drawn from an exogenous distribution $G(w)^{4}$.

While employed, on the other hand, agents receive an instantaneous utility (and wage) $w$. Each job can be terminated because an acceptable new offer arrives, or because the worker receives a reallocation shock (for which the resulting new state can be either unemployed or employed in a new job), or due to the arrival of an involuntary separation shock which

\footnotetext{
${ }^{2}$ This means that the instantaneous utility flow enjoyed from a flow of income $y$ is $U(y)=y$.

${ }^{3}$ Participation decisions are not modeled in this paper.

${ }^{4}$ The behavior of firms is not explicitly modeled and it is assumed that it is summarized in the wage distribution.
} 
leads directly to the unemployment state. Job offers while employed arrive according to a Poisson process with parameter $\lambda_{E}$ and, as before, they are represented by a wage rate $(w)$ drawn from the distribution $G(w)$. Reallocation shocks, on the other hand, arrive according to a Poisson process with parameter $\lambda_{R}$. When this type of shock arrives the worker's job is terminated and he/she immediately receives a new offer (which can be acceptable or not) without going to the unemployment state. Following Flabbi and Leonardi (2010), this type of shock is incorporated in the model as an alternative to empirically account for jobto-job transition with wage cuts and can be theoretically interpreted as an approximation of institutions such as the advance notice received by the worker when a layoff occurs 5 . Finally, involuntary separations arrive according to a Poisson process with parameter $\eta$. Workers discount the future at an exogenous and constant rate $\rho>0$ and seek to maximize the expected discounted sum of future utility flows.

Denote the value of unemployment by $U$ and the value of employment for a worker whose wage is $w$ by $W(w)$. As is discussed in detail in Flinn (2002) and Flabbi and Leonardi (2010), the optimal decision rules in this model have a reservation value property and they depend on the type of transition. If the agent receives an offer while unemployed, he/she will accept the offer if the wage is greater than the reservation wage $\left(w^{*}\right)$, which satisfies $W\left(w^{*}\right)=U$. The same holds when a worker receives a reallocation shock because his/her alternative state is unemployment. On the other hand, if the agent receives an offer while on the job, the outside option corresponds to the current wage which means that the agent will accept the offer only if the new wage (say $w^{\prime}$ ) is greater than the current wage $(w)$. To summarize the optimal decision rules write:

$$
\begin{aligned}
& d_{U, R}(w)=\left\{\begin{array}{cc}
\text { Accept offer } w & \Longleftrightarrow w \geq w^{*} \\
\text { Unemployment state } & \Longleftrightarrow w<w^{*}
\end{array}\right. \\
& d_{E}(w)=\left\{\begin{array}{c}
\text { Accept new offer } w^{\prime} \quad \Longleftrightarrow w^{\prime} \geq w \\
\text { Continue in current job } \Longleftrightarrow w^{\prime}<w
\end{array}\right.
\end{aligned}
$$

Using the values of unemployment and employment, the decision rules and the parameters, it is possible to write the flow value of unemployment as:

$$
\rho U=b+\lambda_{U} \int_{w^{*}}^{\infty}[W(w)-U] d G(w)
$$

Equation (3.2) indicates that unemployed agents receive a flow utility $b$ and that ate $\lambda_{U}$ they get a job offer, which if taken $\left(w \geq w^{*}\right)$ generates a capital gain of $W(w)-U$. In

\footnotetext{
${ }^{5}$ To account for job-to-job transitions with wage cuts, which conditional on Flinn (2002) model are probability zero events, the literature has typically used measurement error in wages in the estimation (Eckstein and van den Berg, 2007). However, there can be in practice job-to-job transition with wage cuts if other job amenities are considered; but because those amenities are not modeled here, this type of event is inconsistent with the model. Here is where the idea of Flabbi and Leonardi (2010) can be used.
} 
turn, the flow value of taking a job with current wage $w$ can then be written as:

$$
\begin{aligned}
\rho W(w)= & w+\lambda_{E} \int_{w}^{\infty}\left[W\left(w^{\prime}\right)-W(w)\right] d G\left(w^{\prime}\right)+\lambda_{R} \int_{w^{*}}^{\infty}\left[W\left(w^{\prime}\right)-W(w)\right] d G\left(w^{\prime}\right) \\
& +\left(\eta+G\left(w^{*}\right) \lambda_{R}\right)[U-W(w)]
\end{aligned}
$$

According to equation (3.3), an employed agent receives a wage rate $w$ and new offers, reallocation and terminations shocks arrive at rates $\lambda_{E}, \lambda_{R}$ and $\eta$, respectively. In the case of a new offer, if it is good enough, meaning that $w^{\prime} \geq w$, the worker changes his/her job and a capital gain of $W\left(w^{\prime}\right)-W(w)$ is realized. When a reallocation shock arrives, on the other hand, there are two possibilities: if the new offer after the job termination is taken, a realized capital gain (or possibly loss) of $W\left(w^{\prime}\right)-W(w)$ occurs, while if it is not taken, the worker becomes unemployed with a capital loss of $U-W(w)$. Finally, when an involuntary separation occurs the capital loss will also be $U-W(w)$.

Combining equations (3.2) and (3.3) with the equilibrium conditions $W\left(w^{*}\right)=U$ and $W(w)=W\left(w^{\prime}\right)$ that generate the decision rules in (3.1) it is possible to write ${ }^{6}$ :

$$
\begin{aligned}
w^{*} & =\gamma\left(w^{*}\right) b+\left[\gamma\left(w^{*}\right) \lambda_{U}-\lambda_{E}-\lambda_{R}\right] \int_{w^{*}}^{\infty} W\left(w^{\prime}\right) d G\left(w^{\prime}\right) \\
W(w) & =\theta(w)\left\{\begin{array}{c}
w+\left[\eta+\lambda_{R} G\left(w^{*}\right)\right] W\left(w^{*}\right) \\
+\lambda_{E} \int_{w}^{\infty} W\left(w^{\prime}\right) d G\left(w^{\prime}\right)+\lambda_{R} \int_{w^{*}}^{\infty} W\left(w^{\prime}\right) d G\left(w^{\prime}\right)
\end{array}\right\}
\end{aligned}
$$

where $\gamma\left(w^{*}\right)=\frac{\left(\rho+\left(\lambda_{E}+\lambda_{R}\right) \widetilde{G}\left(w^{*}\right)\right)}{\left(\rho+\lambda_{U} \widetilde{G}\left(w^{*}\right)\right)}$ and $\theta(w)=\frac{1}{\left(\rho+\eta+\lambda_{R}+\lambda_{E} \widetilde{G}(w)\right)}$

The first equation solves for the reservation wage $w^{*}$, while the second solves for the function $W(w)$. Once both are known, the solution of the model is fully characterized, and for a given set of parameters and assumptions about the parametric form of the wage distribution, can be used to simulate labor market careers. It is important to mention that it is possible to show that Blackwell's sufficient conditions hold and, therefore, there is a unique fixed point for $w^{*}$ and $W(w)$.

\section{Estimation Procedure}

The model is estimated using Maximum Likelihood Methods with supply side data for the Chilean labor market. This section describes the data available for estimation and briefly discuses the likelihood function, the identification strategy and the potential econometric issues faced in estimation.

\footnotetext{
${ }^{6}$ Appendix A presents the detailed derivation of the equations of the model and the computational algorithm used to solve equations (3.4) and (3.5).
} 
4.1. Data. Estimating job search models with on-the-job search requires a rich environment of information because not only are unemployment to employment transitions needed but also job to job transitions. In other words, information about labor market histories or working cycles is needed (Eckstein and van den Berg, 2007). This feature of the data is hard to find for developing economies which, in part, explains why the literature has concentrated only on the United States, Canada and Europe. This paper uses the Chilean Social Protection Survey (Encuesta de Protección Social or EPS), from the Subsecretaría de Previsión Social of the Chilean government ${ }^{7}$, which was designed precisely to build a panel of labor market histories.

The survey was conducted in 2002, 2004, 2006 and 2009 and in each survey, the interviewer explicitly asked about the events (dates of different states in the job market and average wages in each job) in the years after the last survey in which the individual participated. For the estimations only the surveys conducted in 2004 and 2006 are used, and to avoid left and double censoring in the data, the data of the last spell in the 2002 survey is used to correct the first spells observed in the 2004 survey. The reasons for focusing only on these two surveys are twofold: individuals were asked only about their labor histories but not about the wage in each event in the 2002 survey, and the 2009 survey conveys information contaminated with the effects of the 2008 financial crises on the labor market. In any case, working only with these two surveys generates a time span from January 2002 to September 2007, which means that almost 6 years of labor market transitions are available for the estimation.

Two problem arose in the appending of the 2004 and 2006 surveys. First, there were overlapping events: events at the end of the 2004 survey overlapped with those at the beginning of the 2006 survey. Two overlapped events were merged if they belonged to the same state ${ }^{8}$. Second, there were contained events: events at the end of the 2004 survey were contained in those at the beginning of the 2006 survey. In this case, the events occurring in the 2004 survey were kept since it is assumed that the data on the events that occurred in the same year as the survey is more accurate. As was mentioned before, the last event of the 2002 survey was used only to correct censoring and, in performing this correction, the criteria described above, when overlapping or contained events problems were found, was also used. The only difference is that information on wages was preserved for the employed spells observed at the beginning of the 2004 survey. Finally, individuals who

\footnotetext{
${ }^{7}$ The survey is conducted by the Microdata Center of the Economics Department at the University of Chile with the participation of academics of the University of Pennsylvania and the University of Michigan.

${ }^{8}$ For the case of employed workers and to increase the likelihood of merging two events that belong to the same job, information about the type of contract (permanent, fixed term, per service, etc) was also used.
} 
presented inconsistencies in their histories, had incomplete histories or events with missing information on wages, hours worked or event dates were discarded ${ }^{9}$.

The model assumes that individuals are homogeneous making some sample restrictions necessary in order to guarantee a certain degree of homogeneity consistent with the model. In particular, the estimation sample satisfies the following criteria: males who are actively participating in the labor market and are between 20 and 65 years old. These sample decisions were taken because first, the model presented in the previous section does not explicitly model participation decisions, and second, in the case of women there is a strong selection problem due to participation decisions ${ }^{10}$. Additionally, and because of the important role of education in explaining wage inequality in Chile (Contreras, 2002), the sample was divided into two subsamples by education level: skilled and unskilled workers. The former group consists of individuals who have completed tertiary education (that is, more than 14 years of schooling), while the latter group did not complete that level of education. Initially, there were 2,892 individuals in the sample with these characteristics (once the inconsistencies were discarded), 688 skilled workers and 2,207 unskilled workers.

The sample size was further reduced due to other problems with the data. First, there were double censored spells in the unemployment state, which could not be used because they generate an identification problem as discussed in the next section (fortunately this reduction only represents $1.9 \%$ of the valid sample). Second, to avoid an outliers problem, due to the existence of unrealistically high wages, 5 of the upper and lower percentiles in wages were dropped from the sample (resulting in a reduction of $15 \%$ of the valid sample observations). This elimination generated an average wage that is comparable with the literature $^{11}$.

The final sample was then organized in working cycles. Each cycle starts in the unemployment state which is followed by all observed job to job transitions (note that it is possible to observe more than one cycle per individual). Working cycles starts in this state because it resets the dynamics of the model (Flabbi and Leonardi, 2010). If for some individual, the first event, observed in January 2002, corresponds to an employment state, all transitions were also stored for estimation purposes. However, information differentiating both types of cycles, either starting in unemployment or starting in employment, was stored and exploited in the estimation. Figure 3 shows how the cycle is constructed for a

\footnotetext{
${ }^{9}$ This group of individuals with inconsistencies and missing data represented around $18 \%$ of the sample.

${ }^{10}$ According the National Institute of Statistics of Chile the average participation rates in the 2000s were 74 and $38 \%$ for men and women, respectively

${ }^{11}$ Fuentes et al. (2005), using the National Socio-economic Survey (CASEN), estimate that in 2003 the average monthly real labor income for males was 267,378 pesos (in 2004 pesos). Assuming an average of 48 working hours per week, an hourly wage of 1392.59 Chilean pesos (or 2.28 US dollars) can be estimated.
} 
hypothetical example of labor market history. After all data manipulations, the estimation has a total of 693 and 2,572 cycles for skilled and unskilled workers, respectively.

It is useful to summarize the information available for estimation and to define the notation used in the likelihood function in the following way:

$$
\left\{t_{k}(i), w_{k}(i), c_{k}(i), r_{k}(i), \chi(i)\right\}_{i=1}^{N^{C}}
$$

where: $N^{C}$ represents the number of cycles observed in the sample, $t_{k}(i)$, for $k=u, 1,2,3$, corresponds to duration information, measured in months, for the $k^{\text {th }}$ state in the cycle. Note that $t_{1}(i)$ represents the duration of both the first job after the unemployment state and the duration of the first observed job when the cycle starts in an employment state. On the other hand, $w_{k}(i)$, for $k=u, 1,2,3$, is the wage measured in 2004 U.S. dollars per hour for the $k^{\text {th }}$ state in the cycle. Note that $w_{u}(i)$ corresponds to the first accepted wage out of the unemployment state while $w_{1}(i)$ corresponds to the wage observed in a cycle that starts in an employment state. Left censored spells are represented by $c_{k}(i)$, for $k=u, 1,2,3$, which are dummy variables that take the value 1 if the spell is censored and zero otherwise. Terminations in unemployment are indicated by $r_{k}(i)$, for $k=1,2,3$, which are dummy variables that take the value 1 if a transition between employment and unemployment is observed and zero otherwise. This also means that the cycle is complete. Finally, $\chi$ indicates if the cycle starts in a unemployment state. It is a dummy variable that takes the value 1 if the unemployment state is observed at the beginning of each cycle and zero otherwise.

Tables 1 and 2 present descriptive statistics on duration and hourly wages in each state of the cycle, differentiating by the nature of the first event of the cycle (unemployment state or employment state) and by level of education. With respect to the duration information, Table 1 indicates that while skilled workers remain unemployed on average two more months than unskilled workers, they keep their jobs for longer periods compared to the unskilled workers. This is true when the cycle starts in an unemployment spell. On the other hand, when the cycle starts in an employment spell, such differences in the average job duration are not that evident, at least in the case of the first observed job. When the cycle starts in an unemployment spell, the right censoring problem is important because more than $20 \%$ of the spells in the unemployment state and in the first job are censored. When the cycle starts in employment, however, this problem becomes even more important. Hence the estimation method has to control for this problem in order to avoid censoring bias. The left censored problem does not represent an issue because less than $2 \%$ of the spells have unknown starting date.

Wages information, in table 2, shows that in the first job, after being in an unemployment state, skilled workers earn, on average, twice that earned by an unskilled worker. This gap gets even larger in the following job in the cycle. In the transition from the first job, after 
unemployment, to the second job more than $40 \%$ of the wages fall. This figure increases to more than $80 \%$ in the transition to the third job. However, this drops in wages should not be large in magnitude because, on average, wages grow in each of these transitions. When the cycles start in an employment state the gaps between wages of skilled and unskilled workers are similar to those observed when the cycle starts in an unemployment state. In terms of wage cuts, however, the story is different. Even though in the transition of the first to the second job only $10 \%$ of the wages fall, the average wage experiences a reduction. This means that the magnitudes of the wage reductions are large. In the transition to the third job, almost $75 \%$ of the wages fall and as a result the average wage also falls. Finally, it is evident that the distribution of wages is more disperse for skilled workers.

4.2. The likelihood Function. The estimation procedure used in this paper, as well as its description, follows Flabbi and Leonardi (2010) closely. However, before presenting the likelihood function, it is important to discuss the fundamental problem faced in estimating search models with on-the-job search with working cycles that start in an employment state: the initial condition problem ${ }^{12}$. Note from the model in section 3 that an individual who starts in an unemployment state draws an acceptable wage from a distribution truncated at $w^{*}$, that is: $\frac{\int_{w^{\star}}^{\infty} g(w)}{1-G\left(w^{\star}\right)}$. When on the job, on the other hand, the worker draws an acceptable wage from a distribution truncated at its current wage $w_{k}$ with $k=u, 2,3, \ldots$, that is $\frac{\int_{w_{k}}^{\infty} g(w)}{1-G\left(w_{k}\right)}$. Because, by construction, $w_{3} \geq w_{2} \geq w_{u}$ the distribution of the $k^{\text {th }}$ job stochastically dominates (at least weakly) the distribution of the $k^{\text {th }}-1$ job. Therefore, order matters. Now lets consider a worker observed for the first time in an employment state. Without any information on the previous states in the labor market it is impossible to know the order of the job, and hence the distribution that generates the wage. This has implications for the contribution of wages to the likelihood function because those contributions are related precisely with that unknown distribution.

The literature has proposed procedures to address this problem. One option, described in Flinn (2002), is to find the steady state distribution of wages and assume that the system has reached that state. Another alternative, proposed by Ridder and van den Berg (2003) and used to estimate the arrival rates, uses only data on duration and the wage distribution of the workers initially observed after unemployment. Barlevy and Nagaraja (2010) goes further and propose a method, suitable under some particular assumptions, to estimate these rates using only duration data and completely ignoring wage information (in particular, it exploits heterogeneity in the hazard rates). A third option, used by Flinn (2002) and Flabbi and Leonardi (2010), is to write the likelihood conditioning on the wage of the first

\footnotetext{
${ }^{12}$ In this paper the discussion is rather brief and informal. For a formal exposition of the problem see Flinn (2002).
} 
job observed at the beginning of the sample (that is, the first job of the cycles that starts in employment). This last procedure generates consistent estimates at the cost of losing some information.

With respect to the first option, since more than a third of the sample, used in the estimations, correspond to young workers (i.e., those less than 35 years old), it is inappropriate to make the assumption that system has reached the steady state for this group of workers. On the other hand, since the analysis of lifetime inequality requires both, the transitions across the state and the wage distribution, the second group of approaches provide only partial information. Hence, given this reasons, the third approach is the most suitable for the particular application of this paper.

To construct the likelihood function it is necessary to define the contributions of the data in each state to that function. In order to describe the contribution of the duration data, the hazard rate in all states (that is, the probability of termination of the state conditional on its survival up to this point) must first be defined. Conditional on the model, when the individual is unemployed the hazard rate is:

$$
h_{u}=\lambda_{u}\left(1-G\left(w^{*}\right)\right)=\lambda_{u} \widetilde{G}\left(w^{*}\right)
$$

that is, the probability that an acceptable offer arrives. On the other hand, and again conditional on the model, when the individual is employed the hazard rate is:

$$
h_{e}(w)=\lambda_{E}(1-G(w))+\lambda_{R}+\eta=\lambda_{E} \widetilde{G}(w)+\lambda_{R}+\eta
$$

or the probability of termination of the current job due to the arrival of an acceptable offer, the occurrence of a reallocation shock or the realization of an involuntary separation shock. These rates are constant, implying that the density of a complete spell in each state can be characterized by a negative exponential distribution with parameter equal to the hazard rate $^{13}$.

To write the contribution to the likelihood of the durations of unemployment and employment states it is important to be aware that the data can be right censored, that is the end of a particular state is later than the last observed date ${ }^{14}$. In the unemployment state, and given the hazard rate $h_{u}$, the contribution of the unemployment duration to the likelihood for a complete spell and for a right censored spell, respectively, is defined as

\footnotetext{
${ }^{13}$ This is $f(t)=h \exp (-h t)$ for $t>0$.

${ }^{14}$ The estimation does not correct for left censored spells because they represent only a small number of observations (see table 2). Cycles with double censored spells, on the other hand, are ignored because of an identification problem. As is noted by (Flinn, 2002), when there are events in which an individual is continuously unemployed, the parameters of the model are not identified since permanent unemployment can be produced by $\lambda_{U}=0, \eta=1, b=1$ or by any combination of these conditions. Fortunately these observations consisted only of $1.9 \%$ of the sample.
} 
follows:

$$
\begin{aligned}
f_{u}\left(t_{u}\right) & =h_{u} \exp \left(-h_{u} t_{u}\right) \\
f_{u}\left(t_{u}, c_{u}^{r}=1\right) & =\operatorname{Pr}\left[T>t_{u}\right]=\exp \left(-h_{u} t_{u}\right)
\end{aligned}
$$

On the other hand, given the hazard rate $h_{e}(w)$ the contributions of the employment duration to the likelihood when the spells are complete, which depends on the conditions of termination of this state, are:

$$
\begin{aligned}
f_{e}\left(t_{k}, r_{k}=1 \mid w_{k}\right) & =h_{e}\left(w_{k}\right) \exp \left(-h_{e}\left(w_{k}\right) t_{k}\right) \frac{\lambda_{R} G\left(w^{*}\right)+\eta}{h_{e}\left(w_{k}\right)} \\
f_{e}\left(t_{k}, w_{k+1}>w_{k} \mid w_{k}\right) & =h_{e}\left(w_{k}\right) \exp \left(-h_{e}\left(w_{k}\right) t_{k}\right) \frac{\left(\lambda_{R}+\lambda_{E}\right) \widetilde{G}\left(w_{k}\right)}{h_{e}\left(w_{k}\right)} \\
f_{e}\left(t_{k}, w_{k+1}<w_{k} \mid w_{k}\right) & =h_{e}\left(w_{k}\right) \exp \left(-h_{e}\left(w_{k}\right) t_{k}\right) \frac{\lambda_{R}\left[G\left(w_{k}\right)-G\left(w^{*}\right)\right]}{h_{e}\left(w_{k}\right)}
\end{aligned}
$$

In equation (4.3) the density of duration is adjusted by the probability of transit to unemployment (due to the arrival of a reallocation shock or an involuntary separation shock) conditional on leaving from a job with wage $w_{K}$. In equation (4.4) the adjustment is made with the probability of leaving to a job with higher wage (due to the arrival of a new job offer or a reallocation shock), and again, conditional on leaving from a job with wage $w_{K}$. Finally, in equation (4.5) the adjustment is incorporated with the probability of leaving to a job with lower wage (which can occur only if a reallocation shock, that does not terminate in unemployment, is realized). It is important to note that each contribution in equations (4.3) to (4.5) is conditional on the wage of the current spell. Finally, with right-censored spells we have the following contribution of the employment duration to the likelihood (in this case, the condition of termination is unknown):

$$
f_{e}\left(t_{k}, c_{k}^{r}=1 \mid w_{k}\right)=\exp \left(-h_{e}\left(w_{k}\right) t_{k}\right)
$$

To define the contribution of wages to the likelihood it is important to take into account that accepted wages are observed in the data. Conditional in the model, that is using the decision rules in (3.1), it is possible to write the contributions of accepted wages in each state of the cycle as:

$$
\begin{aligned}
f_{w}\left(w_{u}\right) & =\frac{g\left(w_{u}\right)}{\widetilde{G}\left(w^{*}\right)} \\
f_{w}\left(w_{k+1}, w_{k+1}>w_{k} \mid w_{k}\right) & =\frac{g\left(w_{k+1}\right)}{\widetilde{G}\left(w_{k}\right)} \frac{\left(\lambda_{E}+\lambda_{R}\right) \widetilde{G}\left(w_{k}\right)}{\lambda_{E} \widetilde{G}\left(w_{k}\right)+\lambda_{R} \widetilde{G}\left(w^{*}\right)} \\
f_{w}\left(w_{k+1}, w_{k+1}<w_{k} \mid w_{k}\right) & =\frac{g\left(w_{k+1}\right)}{\widetilde{G}\left(w^{*}\right)} \frac{\lambda_{R}\left(G\left(w_{k}\right)-G\left(w^{*}\right)\right)}{\lambda_{E} \widetilde{G}\left(w_{k}\right)+\lambda_{R} \widetilde{G}\left(w^{*}\right)}
\end{aligned}
$$


where $g(\cdot)$ and $G(\cdot)$ are the pdf and cdf functions, respectively. Equation (4.7) is simply the density of an acceptable offer when leaving the unemployment state (that is, it is a truncation of the wage density at the reservation wage $\left.w^{*}\right)$. On the other hand, in equations (4.8) and (4.9) information on the behavior of wages, when job to job transition are observed, is incorporated because both cases have different implications in terms of the model. In equation (4.8) the joint density of observing $w_{k+1}$ and a wage growth is the density of wages $g\left(w_{k+1}\right)$ truncated at the current wage $w_{k}$ times the probability of observing a wage growth (after receiving a new offer or a reallocation shock) conditional on leaving that job. Equation (4.9) has a similar interpretation but with a wage cut.

The model incorporates a reallocation shock to empirically account for job to job transition with wage cuts. However, given the self-reported and retrospective nature of the data, it is highly likely that wages are measured with error ${ }^{15}$. If wages are measured with error, the observed wage is $w^{o}=w \varepsilon$ where the measurement error $\varepsilon$ has a c.d.f. $Q(\varepsilon)$ and p.d.f. $q(\varepsilon)$ (see, for example, Wolpin, 1987; van den Berg and Ridder, 1998). The c.d.f. of the observed wage is, therefore, $Q\left(\frac{w^{o}}{w}\right)$ which means that the density of the observed wages takes the form of $\frac{1}{w} q\left(\frac{w^{0}}{w}\right)$. The question that arises at this point is how to differentiate a wage cut due to a reallocation shock and to measurement error. To isolate this question, the probability of a wage growth in terms of the observed wages is first defined:

$$
P\left(w_{k+1}>w_{k}\right)=\phi\left(w_{k}^{o}, w_{k+1}^{o}\right)=P\left(\frac{\varepsilon_{k}}{\varepsilon_{k+1}}>\frac{w_{k}^{o}}{w_{k+1}^{o}}\right)
$$

The bigger the difference between two consecutive observed wages the higher the probability of observing a change in true wages (this works in both directions with $P\left(w_{k+1}>\right.$ $\left.w_{k}\right)=\phi\left(w_{k}^{o}, w_{k+1}^{o}\right)$ and $\left.P\left(w_{k+1}<w_{k}\right)=1-\phi\left(w_{k}^{o}, w_{k+1}^{o}\right)\right)$. This implies that smaller changes in observed wages are considered as measurement error. It is now possible to write the density of the observed wages by integrating over the support of the (true) accepted wages

$$
\begin{aligned}
f_{w}\left(w_{u}^{o}\right) & =\int_{w^{*}} \frac{1}{w_{u}} q\left(\frac{w_{u}^{o}}{w_{u}}\right) f_{w}\left(w_{u}\right) d w_{u} \\
f_{w}\left(w_{k+1}^{o} \mid w_{k}\right) & =\phi\left(w_{k}^{o}, w_{k+1}^{o}\right) \int_{w_{k}} \frac{1}{w_{k+1}} q\left(\frac{w_{k+1}^{o}}{w_{k+1}}\right) f_{w}\left(w_{k+1}, w_{k+1}>w_{k} \mid w_{k}\right) d w_{k+1} \\
& +\left(1-\phi\left(w_{k}^{o}, w_{k+1}^{o}\right)\right) \int_{w^{*}} \frac{1}{w_{k+1}} q\left(\frac{w_{k+1}^{o}}{w_{k+1}}\right) f_{w}\left(w_{k+1}, w_{k+1}<w_{k} \mid w_{k}\right) d w_{k+1}
\end{aligned}
$$

\footnotetext{
${ }^{15}$ As is common in the literature, it is assumed that measurement error is present in wage data but not in duration data (Eckstein and van den Berg, 2007; Flinn, 2006).
} 
Due to space considerations the full likelihood function, using all the elements presented in this subsection, is presented in Appendix $\mathrm{B}^{16}$. Here however, as illustration, two examples are presented. First, the individual likelihood of a cycle that starts in unemployment, has no right censored duration in unemployment but has right censored duration in the first job is defined as:

$$
L\left(\chi=1, c_{u}=0, c_{1}=1\right)=f_{u}\left(t_{u}\right) \int_{w^{*}} f_{e}\left(t_{1}, c_{1}=1 \mid w_{u}\right) \frac{1}{w_{u}} q\left(\frac{w_{u}^{o}}{w_{u}}\right) f_{w}\left(w_{u}\right) d w_{u}
$$

The second example is related with the individual likelihood of a cycle that starts in unemployment, has no right censored duration in the unemployment spell and in the first and second jobs, and terminates in unemployment after the second job (complete cycle):

$$
\begin{aligned}
& L\left(\chi=1, c_{u}=0, c_{1}=0, r_{1}=0, c_{2}=0, r_{2}=1\right)= \\
& \phi\left(w_{u}^{o}, w_{2}^{o}\right)\left[\begin{array}{c}
f_{u}\left(t_{u}\right) \int_{w^{*}} f_{e}\left(t_{1}, w_{2}>w_{u} \mid w_{u}\right) \frac{1}{w_{u}} q\left(\frac{w_{u}^{o}}{w_{u}}\right) f_{w}\left(w_{u}\right) \\
\int_{w_{2}} f_{e}\left(t_{2}, r_{2}=1 \mid w_{2}\right) \frac{1}{w_{2}} q\left(\frac{w_{2}^{o}}{w_{2}}\right) f_{w}\left(w_{2}, w_{2}>w_{u} \mid w_{u}\right) d w_{2} d w_{u}
\end{array}\right] \\
& +\left(1-\phi\left(w_{u}^{o}, w_{2}^{o}\right)\right)\left[\begin{array}{c}
f_{u}\left(t_{u}\right) \int_{w^{*}} f_{e}\left(t_{1}, w_{2}<w_{u} \mid w_{u}\right) \frac{1}{w_{u}} q\left(\frac{w_{u}^{o}}{w_{u}}\right) f_{w}\left(w_{u}\right) \\
\int_{w_{2}} f_{e}\left(t_{2}, r_{2}=1 \mid w_{2}\right) \frac{1}{w_{2}} q\left(\frac{w_{2}^{o}}{w_{2}}\right) f_{w}\left(w_{2}, w_{2}<w_{u} \mid w_{u}\right) d w_{2} d w_{u}
\end{array}\right]
\end{aligned}
$$

In the estimation two standard assumptions are made. First, $G(\cdot)$ is a lognormal probability distribution function with parameters $(\mu, \sigma)$ and second, $Q(\cdot)$ is a lognormal probability distribution function with parameters $\left(\mu_{\varepsilon}, \sqrt{-2 \mu_{\varepsilon}}\right)^{17}$. These two assumptions imply that $\left(w_{k}^{o}, w_{k+1}^{o}\right)$ are jointly lognormal, which makes the computation of $\phi\left(w_{k}^{o}, w_{k+1}^{o}\right)$ easier. Finally, it is important to mention that all the parameters in the model are identified ${ }^{18}$. The identification strategy relies on, and is extensively discussed in, Flinn and Heckman (1982) (recoverability conditions and unemployment-employment transitions), Flinn (2002) (jobto-job transitions) and Flabbi and Leonardi (2010) (job-to-job transition with wage cuts).

\section{Results}

5.1. Estimation Results. Table 3 presents the maximum likelihood estimates of the model parameters $\left(\lambda_{U}, \lambda_{E}, \lambda_{R}, \eta, \mu, \sigma, \mu_{\varepsilon}, b\right)$ and the reservation wage $w^{*}$ for all workers (first column) and separately for skilled and unskilled workers (second and third columns, respectively). The estimation, when all workers are pooled together, hides important differences in the dynamics of the labor market by education level. As expected, this is particularly

\footnotetext{
${ }^{16}$ As in Flinn (2002) and Flabbi and Leonardi (2010) only two consecutive jobs are used as a job to job transition because when the number of transitions grows the likelihood becomes rapidly intractable.

${ }^{17}$ This is a consequence of two assumption (1) $E(\varepsilon \mid w)=1$ and (2) lognormality.

${ }^{18}$ Parameters $\rho$ and $b$ cannot be identified separately, but if a value of $\rho$ is assumed then $b$ can be recovered from equation (3.4). In the particular case analyzed, $\rho$ is defined as 0.065 in annualized terms (see, for example, Fuenzalida and Mongrut, 2010).
} 
true for the parameters that govern the wage distributions and for the reservation wages. Also, it is observed that the arrival rate of the reallocation shock, $\lambda_{R}$, is virtually zero for all samples, which means that the observed wage cuts are small enough so they are absorbed by the measurement error instead of representing drops in the true wages ${ }^{19}$.

The estimates of the arrival rates of job offers while unemployed $\lambda_{U}$ imply that workers should on average expect offers every 11 months. This implies that it takes time to leave the unemployment state. This phenomena is more pronounced for the skilled worker because they should expect offers almost every 15 month (compared with slightly less than 11 months for unskilled workers). This result is qualitatively different from the findings of Flabbi and Leonardi (2010) for the U.S. economy and could indicate that in the Chilean labor market for skilled workers is tighter. On the other hand, the arrival rate of offers while on the job, $\lambda_{E}$, indicate that new job opportunities do not arrive often in the Chilean labor market. In particular, an employee should expect the arrival of new job opportunities every 9 years, on average. It is also observed that, compared with skilled workers, the unskilled workers are less fortunate in receiving job offers while on the job. Indeed, job opportunities arrive on average every 7 and 12 years for skilled and unskilled workers, respectively. Estimates of the arrival rates of involuntary separations, $\eta$, in turn, indicates that it is not common to observe termination due to this type of shock because it takes, on average, more than 50 years to receive an involuntary separation shock for all samples. The findings for $\lambda_{E}$ and $\eta$ combined indicate that jobs are very persistent in the Chilean labor market.This result is consistent with Huneeus and Repetto (2005) findings.

The reservation wage in the Chilean labor market is 1.1 U.S. dollar per hour. As was mention before, this figure hides important differences by education level. In particular, the reservation wage for skilled workers is 3.5 U.S. dollars per hour, while for unskilled workers it is 0.7 U.S. dollars per hour. Hence, skilled workers request a wage that is 5 times the wage requested by unskilled workers in order to accept a job while unemployed. The estimates of the parameters that govern the wage distribution, that is $\mu$ and $\sigma$, imply an average offered wage of 2.3 U.S. dollar per hour, this average being 4.6 and 1.8 U.S. dollars per hour for skilled and unskilled workers, respectively. Therefore, skilled workers earn on average more than twice that earned by unskilled workers. On the other hand, the standard deviations of wages is around 0.45 U.S. dollar per hour with almost no difference across education level. The values of the estimates for the reservation wage and for the parameters of the wages distribution imply that the average accepted wages are on an order of magnitude similar to the average offered wages for all samples. Finally, mention

\footnotetext{
${ }^{19}$ The model without measurement error was also estimated but the fit of the model with measurement error was better in terms of matching the level and the dispersion of the cross-section wage distribution. These estimates are available by request.
} 
about the estimates of the measurement error distribution parameters is pertinent. The distribution of the measurement error is more dispersed for skilled workers (recall that $\sigma_{\varepsilon}=\sqrt{-2 \mu_{\varepsilon}}$ ) indicating that bigger measurement errors are more likely in the observed wages of this group of workers.

5.2. Cross-Section vs. Lifetime Inequality. In order to generate lifetime inequality indices, it is necessary first to construct measures of long-run welfare. To achieve that goal a simulation method was used. In particular, using the point estimated parameters in table 3, the model was simulated to construct labor market careers of 45 years for 10,000 individuals as in Flinn (2002). To preserve the relative weights of the composition between the groups with different education levels, $21 \%$ of those individuals were simulated using the skilled worker estimated parameters while the rest were simulated using the estimated parameters of the unskilled workers. In the simulation each individual started its career in the unemployment state ${ }^{20}$ and in each period a wage and duration were drawn from the appropriate distributions. In the case of the former, a lognormal distribution truncated at the reservation wage or at the current wage, depending on the type of transition, was used, while in the case of the latter the relevant distribution was the exponential distribution. Once the careers were simulated, the long-run (or lifetime) welfare for an individual $i$ was calculated as the sum of the discounted value of his labor income in each state (Flabbi and Leonardi, 2010), that is:

$$
L W_{i}=\sum_{j=1}^{J} \exp \left(-\rho t_{j}\right) \int_{t_{j}}^{t_{j+1}} y_{i j} \exp (-\rho v) d v
$$

where $y_{i j}=b$ if the spell $j$ is unemployment, $y_{i j}=w_{i j}$ if the spell $j$ is employment, $t_{j}$ is the duration of the spell $j$ and $J$ is the total number of spells (note that $\sum_{j=1}^{J} t_{j}=540$ months). In equation 5.1 each flow income in the career is discounted to the beginning of the spell for which it was valid and then all these discounted values were again discounted to the beginning of the period. It is important to mention that the first unemployment spell was dropped because it violates the steady state condition of the flows of the labor market (all the individuals are unemployed).

In addition to the construction of the lifetime welfare measures, a distribution of crosssection measure of labor incomes can also be extracted from the simulations. This is particularly useful to asses the fit of the model in matching moments of that distribution with those observed in the data ${ }^{21}$. The cross-section measure of labor incomes is just the average hourly wage in the $11^{\text {th }}$ year of the career. Like in Flinn (2002) and Flabbi and Leonardi

\footnotetext{
${ }^{20}$ This can be interpreted as an individual looking for a job for the first time.

${ }^{21}$ In order to compare this generated cross-section distribution with the observed in the data, the former has to be adjusted to include the measurement error. This can be done generating random numbers from a lognormal distribution using the parameters estimated in table 3 for the measurement error.
} 
(2010), the Generalized Entropy classes of inequality indices are used to judge the degree of inequality in both the cross-section measure of labor income and the lifetime measure welfare. The Generalized Entropy inequality index with parameter $\alpha$ is defined by ${ }^{22}$ :

$$
G E(\alpha)=\frac{1}{\alpha(\alpha-1)}\left[\frac{1}{N} \sum_{i=1}^{N}\left(\frac{y_{i}}{\bar{y}}\right)^{\alpha}-1\right]
$$

Given the important difference in the labor market dynamics by level of education, it is also useful to decompose the inequality indices to see if the overall inequality reflect differences within skill groups or differences between skill groups. The decomposition used is the following (Jenkins and Van Kerm, 2011):

$$
G E(\alpha)=G E^{B}(\alpha)+G E^{W}(\alpha)
$$

The within-group inequality can be calculated for $M$ subgroups as follows:

$$
G E^{W}(\alpha)=\sum_{m=1}^{M}=\theta_{m}^{\alpha} \psi_{m}^{1-\alpha} G E_{m}(\alpha)
$$

where $\theta_{m}$ is subgroup m's share of total income, $\psi_{m}$ is m's population share, and $G E_{m}(\alpha)$ is the inequality within group $m$. Between-group inequality, $G E^{B}(\alpha)$, can be calculated by imputing the mean income of each subgroup to all the individuals in that subgroup.

Table 4 shows the inequality indices, for $\alpha=0,1,2$, calculated using the lifetime welfare measures (upper panel), the simulated cross-section earnings (middle panel) and a crosssection of earnings extracted from the data (lower panel). In each panel the decomposition described above by education level is also presented. Before discussing the findings in lifetime inequality, a discussion about the extent to which the model is able to replicate the data in the cross-section is necessary. Comparing the middle with the lower panels of table 4 , it is evident that the model tends to overestimate the level of inequality and this occurs not only with the total sample but also by skill level. The difference also becomes higher when more weight is given to the differences in income shares among the rich (that is $\alpha$ if higher). For this reason, the estimates with lower values of $\alpha$ will receive more weight in the conclusions. On the other hand, the model is successful in preserving the inequality ordering observed in the data, that is, the inequality tends to be higher for the skilled workers; and the source of inequality, for both skilled and unskilled workers, is primarily differences in earnings within groups. The model also delivers relatively close estimates of the average earnings for all samples and by skill level.

\footnotetext{
${ }^{22}$ As Cowell (2000) mentions, any measure of inequality should satisfy (1) Anonymity (the metric does not depend on who is the individual), (2) Scale independence (the metric is independent of the aggregate level of income), (3) Population independence (the metric does not depend on the size of the population), and (4) Transfer principle (the metric has to decrease if there are transfers from rich to poor agents). The Generalized Entropy inequality indices satisfy these axioms.
} 
The estimates of lifetime inequality, in the upper panel of table 4, indicates that inequality in the Chilean labor market is not only high at the cross-section level but also from a lifetime perspective. Even though these estimates can be slightly overestimating the true level of inequality, given the discussion in the previous paragraph, it is still high. This is reinforced by the fact that the lifetime inequality estimates use the true earnings instead of the earnings measured with error as in the case of the cross-section inequality measures (the measurement error introduces more variance to the data). As in the cross-section inequality case, lifetime welfare of skilled workers tends to be more unequal when compared with their unskilled counterparts. Also, the primary source of inequality is differences within skilled groups. Finally, the estimates indicate that an average worker in Chile has a lifetime welfare (in this case also earnings) of 25 U.S. dollars per hour, with 35 and 16 U.S. dollars per hour for skilled and unskilled workers, respectively.

\section{EXPERIMENTS}

In this section three experiments were performed in order to closely analyze the sources of the lifetime inequality in the Chilean labor market. First, the lifetime inequality indices are decomposed into two sources, mobility and distribution, to isolate which source has more impact in the total index. Second, the marginal effect on lifetime inequality of each individual parameter is analyzed to find out which parameter or group of parameters, within the mobility and distribution sources, has more impact in the inequality indices. Finally, the effect of age is analyzed by estimating the model with different age groups.

6.1. Lifetime Inequality Decomposition. To decompose the lifetime inequality measures, into inequality due to mobility and inequality due to wage distribution, it is necessary to have a labor market with lower lifetime inequality for comparison purposes (a benchmark). There are two alternatives. The first is to generate a fictitious economy by simply setting the parameters and using that economy as a baseline. The second, and empirically more interesting, is to use a real labor market as a baseline. The question, however, is what labor market is the best to choose. This paper applies this second approach and uses the United States as the benchmark economy. Three reasons are behind this choice. First, this economy has one of the less regulated labor markets worldwide (see figure 1). Considering the differences in the level of regulation in the labor market between Chile and the United States, it will be possible to draw some conclusions regarding the relationship between lifetime inequality and labor market regulation. Second, lifetime inequality measures are lower for this country. Finally, there are comparable estimates, in terms of the model and the sample characteristics, in the literature (Flinn, 2002; Flabbi and Leonardi, 2010, are the obvious choices). 
The decomposition was performed in the following way. Two questions were asked. First, what would happen if the Chilean economy had the same mobility in the labor market as the United States maintaining the features of the wage distribution? Let this be the mobility effect. In this case, the model was simulated with the parameters $\lambda_{U}, \lambda_{E}$ and $\eta$ for the United States and the parameters $\mu, \sigma$ and $b$ for $\mathrm{Chile}^{23}$. Second, what would happen if the Chilean economy had the same wage distribution as the United States while maintaining its mobility level. Let this be the distribution effect. In this case, the model was simulated with the parameters $\lambda_{U}, \lambda_{E}, \lambda_{R}, \eta$, and $b$ for Chile and the parameters $\mu, \sigma$ for the United States. Note that each simulation takes into account all the equilibrium effects of changes in the parameters, that is in each simulation a new reservation wage was found given the new parameters. To analyze quantitatively the importance of these two effects, and following Flabbi and Leonardi (2010), the proportion of the difference in the lifetime inequality index explained by the experiment was calculated, that is:

$$
\Delta(\alpha)^{\text {Experiment }}=\frac{G E(\alpha)^{C H}-G E(\alpha)^{\text {Experiment }}}{G E(\alpha)^{C H}-G E(\alpha)^{U S}}
$$

The inequality indices for the United States were calculated using the simulated careers approach described in section 5 with the parameters estimated by Flinn $(2002)^{24}$. The results of this decomposition are presented in table 5. The upper panel presents the inequality indices generated with the different combination of parameters while the lower panel presents the proportions calculated using equation 6.1.

It can be noticed, comparing the upper panels of table 4 and table 5 , that changing the mobility (in this case increasing it) reduces the level of lifetime inequality substantially. Even though this result is observed for both skilled and unskilled workers, the reduction in the level of inequality is more pronounced for the first group. Additionally, a more mobile labor market also changes the main source of inequality to between groups differences in income. Changing the wage distribution, on the contrary, tends to increase the levels of lifetime inequality. This result is more pronounced for the skilled workers and exacerbates the differences within the skilled group. Lifetime inequality increases, in this case, because even though the average wage in the experiment is higher so is the variance. Clearly, the variance effect dominates, increasing the dispersion of earnings in the lifetime perspective. In quantitative terms, the lower panel of table 5 shows that the reduction in lifetime inequality due to mobility is higher relative to the difference in the lifetime inequality between countries,

\footnotetext{
${ }^{23}$ Given the estimates presented in table 2, the reallocation rate $\lambda_{R}$ was set to zero.

${ }^{24}$ This choice is based only on the differences in lifetime inequality estimates in both countries. The estimates of Flinn (2002) generates lifetime inequality measures that are lower than the estimates of Flabbi and Leonardi (2010) for the United States. Since the goal of this paper is to compare the Chilean economy with an economy that has very different levels of lifetime inequality, the estimates that generate the bigger differences were chosen.
} 
for both skilled and unskilled workers (at least $6.6 \%$ higher). This is not the case for the overall inequality, for which the reduction is only $75 \%$ of the between countries difference in inequality. On the other hand, the increase in inequality due to the wage distribution is at most $58 \%$ of the difference in the inequality index between countries.

This counterfactual experiment indicates that the main source of lifetime inequality in the Chilean labor market, regardless of the education level, is the lack of mobility (relative to the United States labor market). The results show that, in quantitative terms, the effect is not negligible at all. Considering the differences in labor market regulation between Chile and the United States, the last result provides additional empirical evidence in favor of a positive relationship between regulation and inequality, that is a less regulated labor market has more mobility, and therefore less lifetime inequality ${ }^{25}$.

6.2. Marginal Effect of Individual Parameters on Lifetime Inequality. The same simulation approach was used to find the marginal effect of each individual parameter on the lifetime inequality measures. In particular, the model was simulated to create careers changing one parameter in a range of $\pm 25 \%$ while keeping the rest of the parameters at their point estimates. This was done by skill level and the inequality indices, $G(\alpha)$ for $\alpha=0,1,2$, were calculated with the resulting welfare measures. For example, to find the marginal effect of $\lambda_{U}$, for the case of skilled workers, simulations were performed with different values of this parameter in the range of 0.050 and 0.085 while maintaining the other parameters in the estimates (second column) of table 3. As before, the arrival rate of reallocation shocks was set to zero.

The results are shown in figures 4 and 5 for skilled and unskilled workers, respectively. In the case of skilled workers (figure 4), it is evident that the parameter with the greatest impact on the lifetime inequality measures is the arrival rate of job offers while unemployed. In particular, the faster the workers leave the unemployment state, the lower is the lifetime inequality. While on the job, on the other hand, the impact of the arrival rates of job opportunities and involuntary separation shocks is in the same direction of the previous arrival rate, but the size of the impact is by far smaller in these cases. In terms of the distribution parameters, an increase in the mean of the logarithm of wages tends to reduce lifetime inequality and this relationship seems to be nonlinear. In the case of the variance of the logarithm of wages the direction of the effect is not clear.

In the case of unskilled workers (figure 5), it is observed that the results with respect to the mobility parameters are very similar to those observed for skilled workers. The only exception is the arrival rate of the involuntary separation shocks, for which the direction of

\footnotetext{
${ }^{25}$ This result is consistent with Heckman and Pages (2000) findings for Latin American countries. Their results suggest that labor market regulations are an inequality-increasing mechanism. In particular, less-stringent job security tends to be associated with higher turnover and greater flexibility in the labor market.
} 
the impact on lifetime inequality is not clear. With respect to the distribution parameters, the results are the opposite to those found for skilled workers. In particular, while the impact of the mean of the logarithm of wages is not clear, the variance of the logarithm tend to increase lifetime inequality measures. These results, namely a negative marginal effect of mobility parameters on lifetime inequality and an unclear direction of the marginal effect of the distribution parameters on lifetime inequality, reinforce what was found in the decomposition previously discussed.

6.3. Labor Market Mobility by Age. The main result of the decomposition described early in this section was that the lack of mobility is the primary source of lifetime inequality. This subsection tries to go further and analyzes the age dimension of the mobility in the Chilean labor market. This is important because Sapelli (2011), in his extensive analysis of inequality in Chile, finds that changes in cross-section income distribution has been favorable for the younger workers. This exercise seeks to verify this hypothesis in the lifetime dimension. To fulfill this goal, the observed heterogeneity in terms of age is exploited in the estimation of the model. In particular, the model was re-estimated by skill level allowing the arrival rates to vary with different ages while restricting the remaining parameters to be equal across ages ${ }^{26}$. It is assumed that the arrival rates vary with the age groups in a very simple and linear fashion:

$$
\begin{aligned}
\lambda_{U} & =\beta_{1, \lambda_{U}} D_{1}+\beta_{2, \lambda_{U}} D_{2}+\beta_{3, \lambda_{U}} D_{3} \\
\lambda_{E} & =\beta_{1, \lambda_{E}} D_{1}+\beta_{2, \lambda_{E}} D_{2}+\beta_{2, \lambda_{E}} D_{3} \\
\eta & =\beta_{1, \eta} D_{1}+\beta_{2, \eta} D_{2}+\beta_{3, \eta} D_{3}
\end{aligned}
$$

where $D_{1}$ is an indicator variable which is equal to 1 if the individual was born between 1971 and 1986 (that is, he was 20-35 years old in 2006) and zero otherwise, $D_{2}$ is an indicator variable which is equal to 1 if the individual was born between 1961 and 1970 (that is, he was 36-45 years old in 2006) and zero otherwise, and finally, $D_{3}$ is an indicator variable which is equal to 1 if the individual was born between 1941 and 1960 (that is, he was 46-65 years old in 2006) and zero otherwise. In this formulation the parameter $\beta_{i, j}$ represents itself, the arrival rate of the shock $j$ for the age group $i$.

Figures 6 and 7 graphically present the estimated arrival rate for each shock by age groups and a 95\% confidence interval for skilled and unskilled workers, respectively. In the case of the skilled workers (figure 6), there are statistically significant differences in all arrival rates between the younger group $\left(D_{1}\right)$ and the older group $\left(D_{3}\right)$. Unemployed younger workers receive offers almost five times faster than the older workers, which means

\footnotetext{
${ }^{26}$ The model was not estimated as a segmented market by age because of sample size restrictions. The estimates are available upon request.
} 
that the first group leaves the unemployment state faster. On the other hand, when on the job young workers receive new job opportunities more than twice as fast as the older workers. Finally, termination due to involuntary separation is three times more frequent for younger workers compared with the older workers. These last two results indicate that jobs are more persistent for older workers. For the unskilled workers (figure 7), the results are similar, namely there are statistically significant differences in the arrival rates between the younger group and the older group and the magnitudes of these differences are similar to those found for the skilled workers. The main exception is the arrival rate while unemployed where the difference is not as pronounced as in the case of the skilled workers (less than twice). These results and the relation between mobility and lifetime inequality indicate that Sapelli (2011) findings also hold in the lifetime perspective.

Comparing skilled and unskilled workers, the results indicate that offers while unemployed arrive at similar rates for young workers, while for older workers the unskilled group receives their offers three times faster than their skilled counterparts. On the other hand, while on the job unskilled workers receive new job opportunities more often than skilled workers, regardless of the age (the difference is 1.5 times). Finally, unskilled workers experience involuntary separation shocks three times more often, regardless of the age.

\section{Concluding Remarks}

This paper structurally estimates a partial equilibrium search model with on-the-job search using data for the Chilean labor market. The model was estimated separately by education level (skilled vs. unskilled workers). Chile was chosen because it has high and persistent levels of cross-section inequality and it has a rich data set with labor market histories. This is crucial because any attempt to judge lifetime inequality requires both transitions from unemployment to employment and job to job transitions. In order to calculate a long-run measure of welfare, the model and the estimated parameters were used to simulate labor market careers. In particular, the discounted value of the labor income along the career was used as measure of welfare. Finally, the Generalized Entropy family of indices were used to judge the degree of inequality in this measure of welfare.

The estimation results indicate that there are important differences in the dynamics of the labor market by education level. In terms of the transitions across labor market states, the estimated results show that it takes time to leave the unemployment state and this is more pronounced for the skilled worker. On the other hand, new job opportunities do not arrive often in the Chilean labor market and the unskilled workers are less fortunate in receiving job offers while on the job. In turn, involuntary separations are not common to observe. It can be inferred from the last two findings that jobs are very persistent in the Chilean labor market. In terms of the wage distribution, results indicate that skilled workers earn 
on average more than twice that earned by unskilled workers and that the dispersion in the wage distribution by education level is very similar. Finally, with respect to the reservation wages, it was found that skilled workers request a wage that is 5 times the wage requested by unskilled workers, in order to accept a job while unemployed.

The estimates of lifetime inequality show that inequality in the Chilean labor market is not only high at the cross-section level but also from a lifetime perspective. Also, as in the cross-section perspective, lifetime welfare for skilled workers tends to be more unequal when compared with their unskilled counterparts. The decomposition of the inequality indices by education level, on the other hand, shows that the primary source of inequality is differences within skilled groups. Comparing the parameters of the Chilean labor market with those estimated in the literature for the United States labor market (as a benchmark), the lifetime inequality measures were decomposed into mobility effect and distribution effect. This counterfactual exercise indicates that an increase in the mobility of the Chilean labor market substantially reduces the level of lifetime inequality. This is not the case when the wages distribution is changed. Both results hold regardless of the skill level. This implies that the main source of lifetime inequality in the Chilean labor market is the lack of mobility (relative to the United States labor market). Additionally, these results provide additional empirical evidence in favor of a positive relationship between regulation and inequality.

To analyze in more detail the effect of each parameter on the lifetime inequality measures, the marginal effect of each individual parameter was constructed using the same simulation approach. The results indicate that the parameter that affects the most the lifetime inequality measures for both skilled and unskilled workers, that is the transition rate from unemployment to employment, is among the mobility parameters . Finally, the model was re-estimated differentiating the mobility rates by age (three groups were used). This was done to verify whether the recent findings in the literature for Chile, regarding less unequal cross-section earnings distribution observed for the young workers, hold also in the lifetime perspective. Results indicate that there are statistically significant differences in the mobility parameters between the younger workers and the older workers. In particular, unemployed younger workers receive job offers more often than the older workers, while unemployed and on the job. Also, termination due to involuntary separation is more frequent for younger workers. From these results it is possible to infer that jobs are more persistent, and therefore higher lifetime inequality should be expected for older workers. 


\section{Appendix A}

This appendix presents the full derivation of the equations of section 3 and discusses an algorithm to solve the dynamic programing problem. If an infinitesimally small period of time $\Delta t$ is considered, then the value of unemployment is:

$$
U=b \Delta t+\frac{1}{1+\rho \Delta t}\left\{\begin{array}{c}
{\left[\lambda_{U} \Delta t+\sigma(\Delta t)\right] \int \max \left\{U, W\left(w^{\prime}\right)\right\} d G\left(w^{\prime}\right)} \\
+\left(1-\left[\lambda_{U} \Delta t+\sigma(\Delta t)\right]\right) U
\end{array}\right\}
$$

Operating and dividing by $\Delta t$ :

$$
\begin{aligned}
\frac{(1+\rho \Delta t)}{\Delta t} U= & \frac{(1+\rho \Delta t)}{\Delta t} b \Delta t+\frac{\left[\lambda_{U} \Delta t+\sigma(\Delta t)\right]}{\Delta t} \int \max \left\{U, W\left(w^{\prime}\right)\right\} d G\left(w^{\prime}\right) \\
& +\left(\frac{1}{\Delta t}-\frac{\left[\lambda_{U} \Delta t+\sigma(\Delta t)\right]}{\Delta t}\right) U
\end{aligned}
$$

Note that:

$$
\lim _{\Delta t \rightarrow 0} \frac{\sigma(\Delta t)}{\Delta t}=0
$$

Taking $\Delta t \rightarrow 0$ and rearranging:

$$
\rho U=b+\lambda_{U} \int \max \left\{0, W\left(w^{\prime}-U\right)\right\} d G\left(w^{\prime}\right)
$$

Now using the decision rule:

$$
\rho U=b+\lambda_{U}\left(\int_{-\infty}^{w^{*}} 0 d G\left(w^{\prime}\right)+\int_{w^{*}}^{\infty}\left(W\left(w^{\prime}\right)-U\right) d G\left(w^{\prime}\right)\right)
$$

Therefore:

$$
\rho U=b+\int_{w^{*}}^{\infty}\left(W\left(w^{\prime}\right)-U\right) d G\left(w^{\prime}\right)
$$

The value of employment, on the other hand, can be written as:

$W(w)=w \Delta t+\frac{1}{1+\rho \Delta t}\left\{\begin{array}{c}{[\eta \Delta t+\sigma(\Delta t)] U+\left[\lambda_{E} \Delta t+\sigma(\Delta t)\right] \int \max \left\{W(w), W\left(w^{\prime}\right)\right\} d G\left(w^{\prime}\right)} \\ +\left[\lambda_{R} \Delta t+\sigma(\Delta t)\right] \int \max \left\{U, W\left(w^{\prime}\right)\right\} d G\left(w^{\prime}\right) \\ +\left(1-[\eta \Delta t+\sigma(\Delta t)]-\left[\lambda_{E} \Delta t+\sigma(\Delta t)\right]-\left[\lambda_{R} \Delta t+\sigma(\Delta t)\right]\right) W(w)\end{array}\right\}$

Operating and dividing by $\Delta t$ :

$$
\begin{aligned}
\frac{(1+\rho \Delta t)}{\Delta t} W(w)= & \frac{(1+\rho \Delta t) w \Delta t}{\Delta t}+\frac{[\eta \Delta t+\sigma(\Delta t)]}{\Delta t} U \\
& +\frac{\left[\lambda_{E} \Delta t+\sigma(\Delta t)\right]}{\Delta t} \int \max \left\{W(w), W\left(w^{\prime}\right)\right\} d G\left(w^{\prime}\right) \\
& +\frac{\left[\lambda_{R} \Delta t+\sigma(\Delta t)\right]}{\Delta t} \int \max \left\{U, W\left(w^{\prime}\right)\right\} d G\left(w^{\prime}\right) \\
& +\left(\frac{1}{\Delta t}-\frac{[\eta \Delta t+\sigma(\Delta t)]}{\Delta t}-\frac{\left[\lambda_{E} \Delta t+\sigma(\Delta t)\right]}{\Delta t}-\frac{\left[\lambda_{R} \Delta t+\sigma(\Delta t)\right]}{\Delta t}\right) W(w)
\end{aligned}
$$


Taking one more time $\Delta t \rightarrow 0$ and rearranging:

$$
\begin{aligned}
\rho W(w)= & w+\eta(U-W(w))+\lambda_{E} \int \max \left\{0, W\left(w^{\prime}\right)-W(w)\right\} d G\left(w^{\prime}\right) \\
& +\lambda_{R} \int \max \left\{U-W(w), W\left(w^{\prime}\right)-W(w)\right\} d G\left(w^{\prime}\right)
\end{aligned}
$$

Using the decision rule one more time:

$$
\begin{aligned}
\rho W(w)= & w+\eta(U-W(w))+\lambda_{E}\left(\int_{-\infty}^{w} 0 d G\left(w^{\prime}\right)+\int_{w}^{\infty}\left(W\left(w^{\prime}\right)-W(w)\right) d G\left(w^{\prime}\right)\right) \\
& +\lambda_{R}\left(\int_{-\infty}^{w^{*}}(U-W(w)) d G\left(w^{\prime}\right)+\int_{w^{*}}^{\infty}\left(W\left(w^{\prime}\right)-W(w)\right) d G\left(w^{\prime}\right)\right)
\end{aligned}
$$

Note that:

$$
\int_{-\infty}^{w^{*}}(U-W(w)) d G\left(w^{\prime}\right)=(U-W(w)) \int_{-\infty}^{w^{*}} d G\left(w^{\prime}\right)=(U-W(w)) G\left(w^{*}\right)
$$

Therefore:

$$
\begin{aligned}
\rho W(w)= & w+\left(\eta+\lambda_{R} G\left(w^{*}\right)\right)(U-W(w))+\lambda_{E} \int_{w}^{\infty}\left(W\left(w^{\prime}\right)-W(w)\right) d G\left(w^{\prime}\right) \\
& +\lambda_{R} \int_{w^{*}}^{\infty}\left(W\left(w^{\prime}\right)-W(w)\right) d G\left(w^{\prime}\right)
\end{aligned}
$$

It is known that $W\left(w^{*}\right)=U$ and $W(w)=W\left(w^{\prime}\right)$ hold for the reservation wages (in the unemployment state and in the on the job search case, respectively). Using the value of unemployment it is possible to write:

$$
U=\frac{b}{\left(\rho+\lambda_{U} \widetilde{G}\left(w^{*}\right)\right)}+\frac{\lambda_{U}}{\left(\rho+\lambda_{U} \widetilde{G}\left(w^{*}\right)\right)} \int_{w^{*}}^{\infty} W\left(w^{\prime}\right) d G\left(w^{\prime}\right)
$$

Using the value of employment and evaluating in $w^{*}$ :

$$
\begin{aligned}
w^{*}= & \left(\rho+\eta+\lambda_{R}+\lambda_{E} \widetilde{G}\left(w^{*}\right)\right) W\left(w^{*}\right)-\left[\eta+\lambda_{R} G\left(w^{*}\right)\right] U-\lambda_{E} \int_{w^{*}}^{\infty} W\left(w^{\prime}\right) d G\left(w^{\prime}\right) \\
& -\lambda_{R} \int_{w^{*}}^{\infty} W\left(w^{\prime}\right) d G\left(w^{\prime}\right)
\end{aligned}
$$

Now given $W\left(w^{*}\right)=U$ :

$$
w^{*}=\left(\rho+\left(\lambda_{E}+\lambda_{R}\right) \widetilde{G}\left(w^{*}\right)\right) U-\left(\lambda_{E}+\lambda_{R}\right) \int_{w^{*}}^{\infty} W\left(w^{\prime}\right) d G\left(w^{\prime}\right)
$$

Replacing $U$ in the last equation:

$$
w^{*}=\frac{\left(\rho+\left(\lambda_{E}+\lambda_{R}\right) \widetilde{G}\left(w^{*}\right)\right)}{\left(\rho+\lambda_{U} \widetilde{G}\left(w^{*}\right)\right)}\left[b+\lambda_{U} \int_{w^{*}}^{\infty} W\left(w^{\prime}\right) d G\left(w^{\prime}\right)\right]-\left(\lambda_{E}+\lambda_{R}\right) \int_{w^{*}}^{\infty} W\left(w^{\prime}\right) d G\left(w^{\prime}\right)
$$

Naming $\gamma\left(w^{*}\right)=\frac{\left(\rho+\left(\lambda_{E}+\lambda_{R}\right) \widetilde{G}\left(w^{*}\right)\right)}{\left(\rho+\lambda_{U} \widetilde{G}\left(w^{*}\right)\right)}$ then:

$$
w^{*}=\gamma\left(w^{*}\right)\left[b+\lambda_{U} \int_{w^{*}}^{\infty} W\left(w^{\prime}\right) d G\left(w^{\prime}\right)\right]-\left(\lambda_{E}+\lambda_{R}\right) \int_{w^{*}}^{\infty} W\left(w^{\prime}\right) d G\left(w^{\prime}\right)
$$


or alternatively:

$$
w^{*}=\gamma\left(w^{*}\right) b+\left[\gamma\left(w^{*}\right) \lambda_{U}-\lambda_{E}-\lambda_{R}\right] \int_{w^{*}}^{\infty} W\left(w^{\prime}\right) d G\left(w^{\prime}\right)
$$

Now using the value of employment, the fact that $U=W\left(w^{*}\right)$ and calling $\theta(w)=\frac{1}{\left(\rho+\eta+\lambda_{R}+\lambda_{E} \widetilde{G}(w)\right)}$ :

$$
W(w)=\theta(w)\left\{\begin{array}{c}
w+\left[\eta+\lambda_{R} G\left(w^{*}\right)\right] W\left(w^{*}\right) \\
+\lambda_{E} \int_{w}^{\infty} W\left(w^{\prime}\right) d G\left(w^{\prime}\right)+\lambda_{R} \int_{w^{*}}^{\infty} W\left(w^{\prime}\right) d G\left(w^{\prime}\right)
\end{array}\right\}
$$

\section{Algorithm to Solve the Fixed Point}

(1) Construct a grid in $w \in[0, \bar{w}]$. Guess $W_{0}(w)$ (for all values of $w$ in the grid) and $w_{0}^{*}$.

(2) Given $W_{n}(w)$ and $w_{n}^{*}$ calculate $W_{n+1}(w)$ and $w_{n+1}^{*}$ using:

$$
\begin{aligned}
w_{n+1}^{*} & =\gamma\left(w_{n}^{*}\right) b+\left[\gamma\left(w_{n}^{*}\right) \lambda_{U}-\lambda_{E}-\lambda_{R}\right] \int_{w_{n}^{*}}^{\infty} W_{n}\left(w^{\prime}\right) d G\left(w^{\prime}\right) \\
W_{n+1}(w) & =\theta(w)\left\{\begin{array}{c}
w+\left[\eta+\lambda_{R} G\left(w_{n}^{*}\right)\right] W_{n}\left(w_{n}^{*}\right) \\
+\lambda_{E} \int_{w}^{\infty} W_{n}\left(w^{\prime}\right) d G\left(w^{\prime}\right)+\lambda_{R} \int_{w_{n}^{*}}^{\infty} W_{n}\left(w^{\prime}\right) d G\left(w^{\prime}\right)
\end{array}\right\}
\end{aligned}
$$

(3) If $\left|W_{n+1}(w)-W_{n}(w)\right|<\varepsilon$ and $\left|w_{n+1}^{*}-w_{n}^{*}\right|<\varepsilon$, then stop the iteration and the solution is $W_{n+1}(w)$ and $w_{n+1}^{*}$. Otherwise return to 2 with the following updated:

$$
\begin{aligned}
W_{\text {new }}(w) & =W_{n}(w)+\lambda\left(W_{n+1}(w)-W_{n}(w)\right) \\
w_{\text {new }}^{*} & =w_{n}^{*}+\lambda\left(w_{n+1}^{*}-w_{n}^{*}\right)
\end{aligned}
$$




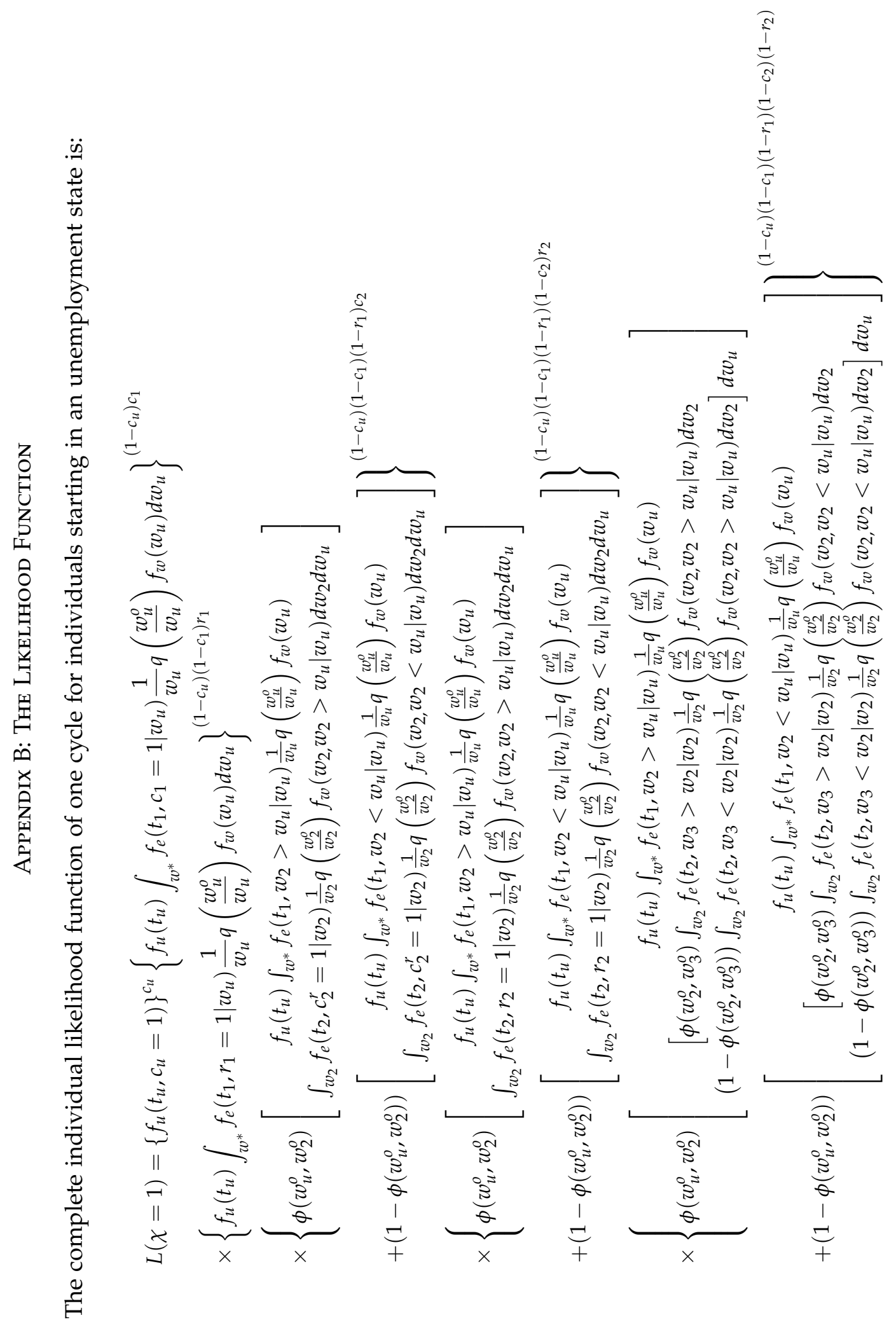




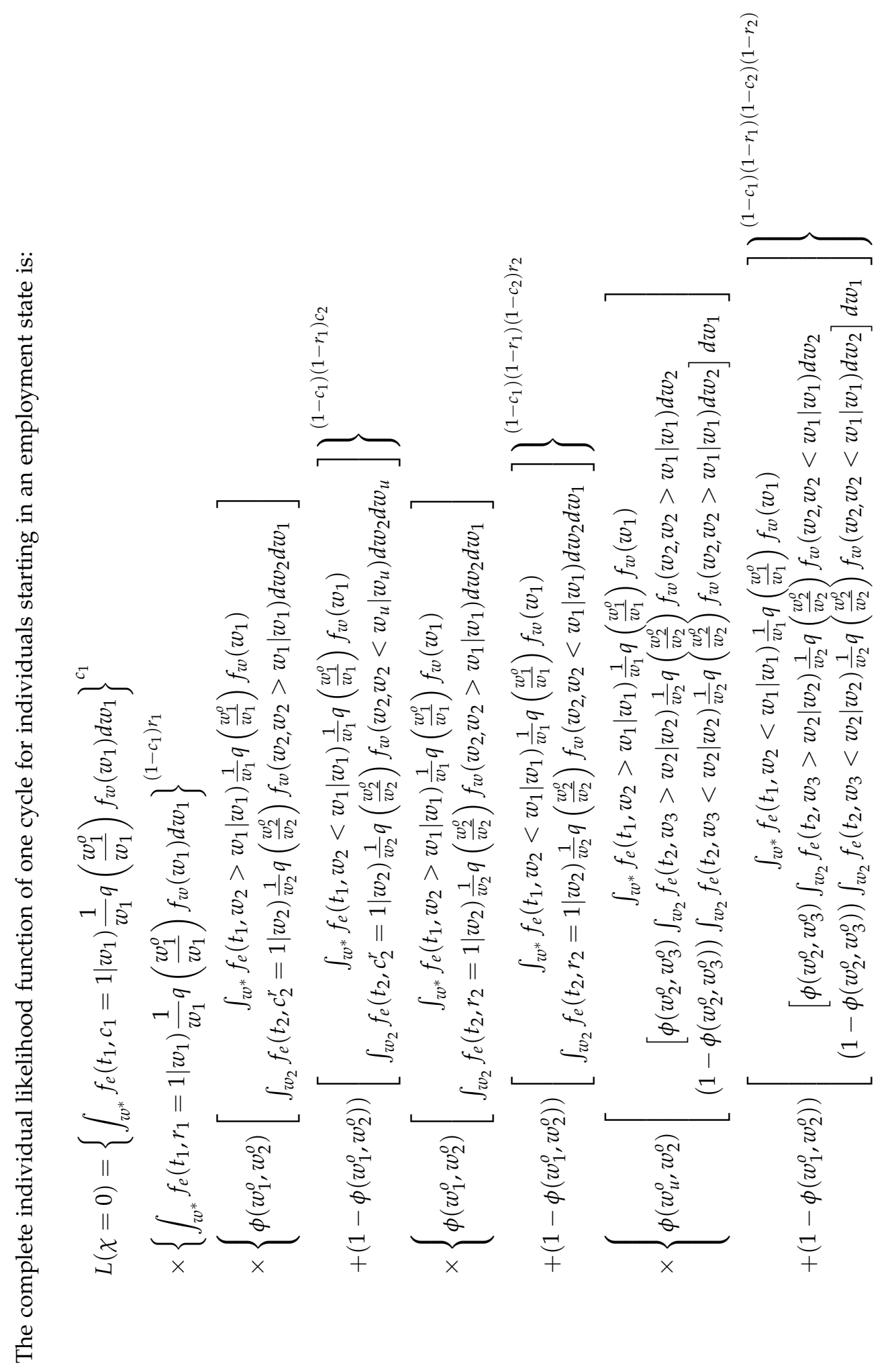




\section{REFERENCES}

Barlevy, Gadi and H. N. Nagaraja, "Estimating Mobility Rates in Search Models with Initial Condition Problems," Review of Economic Dynamics, October 2010, 13 (4), 780-799.

Beyer, Harald, “Logros en Pobreza. Frustración en la Igualdad?," Technical Report 60, CEP - Estudios Públicos 1995.

__ "Distribución del Ingreso: Antecedentes para la Discusión," Technical Report 65, CEP - Estudios Públicos 1997.

Blundell, Richard and Ian Preston, "Consumption Inequality And Income Uncertainty," The Quarterly Journal of Economics, May 1998, 113 (2), 603-640.

Bonhomme, Phane and Jean-Marc Robin, "Assessing the Equalizing Force of Mobility Using Short Panels: France, 1990-2000," Review of Economic Studies, 01 2009, 76 (1), 63-92.

Bowlus, Audra J. and Jean-Marc Robin, "Twenty Years of Rising Inequality in U.S. Lifetime Labour Income Values," Review of Economic Studies, 07 2004, 71, 709-742.

Bravo, David and Alejandra Marinovic, "Wage Inequality in Chile: 40 Years of Evidence," 1997.

Buchinsky, Moshe and Jennifer Hunt, "Wage Mobility In The United States," The Review of Economics and Statistics, August 1999, 81 (3), 351-368.

Chen, Wen-Hao, "Cross-National Differences In Income Mobility: Evidence From Canada, The United States, Great Britain And Germany," Review of Income and Wealth, 03 2009, 55 (1), 75-100.

Contreras, Dante, "Pobreza y Desigualdad en Chile: 1987-92. Discurso, Metodología y Evidencia Empírica," Technical Report 64, CEP - Estudios Públicos 1996.

, "Explaining Wage Inequality in Chile. Does Education Really Matter," Journal of Income Distribution, 2002, 11.

Cowan, K. and José De Gregorio, “Distribución y Pobreza en Chile. Estamos mal? Ha habido progresos? Hemos retrocedido?," Technical Report 64, CEP - Estudios Públicos 1996.

Cowell, F.A., "Measurement of inequality," in Anthony B. Atkinson and François Bourguignon, eds., Handbook of Income Distribution, Vol. 1 of Handbook of Income Distribution, Elsevier, 2000, chapter 2, pp. 87 - 166.

Eckstein, Zvi and Gerard J. van den Berg, "Empirical Labor Search: A survey," Journal of Econometrics, February 2007, 136 (2), 531-564.

Flabbi, Luca and James Mabli, "Household Search or Individual Search: Does it Matter? Evidence from Lifetime Inequality Estimates," Technical Report, Georgetown University, Department of Economics WP 12-02 2010.

and Marco Leonardi, "Sources of earnings inequality: Estimates from an on-the-job 
search model of the US labor market," European Economic Review, 2010, 54 (6), 832 - 854.

Flinn, C. and J. Heckman, "New methods for analyzing structural models of labor force dynamics," Journal of Econometrics, January 1982, 18 (1), 115-168.

Flinn, Christopher J, "Labour Market Structure and Inequality: A Comparison of Italy and the U.S," Review of Economic Studies, July 2002, 69 (3), 611-45.

Flinn, Christopher J., "Minimum Wage Effects on Labor Market Outcomes under Search, Matching, and Endogenous Contact Rates," Econometrica, 07 2006, 74 (4), 1013-1062.

Fuentes, Jeanette, Amalia Palma, and Rodrigo Montero, "Discriminación Salarial por Género en Chile: Una Mirada Global," Estudios de Economía, December 2005, 32 (2 Year 20), 133-157.

Fuenzalida, Darcy and Samuel Mongrut, "Estimation of Discount Rates in Latin America: Empirical Evidence and Challenges," Journal of Economics, Finance and Administrative Science, 2010, 15, 7-44.

Gangl, Markus, "Income Inequality, Permanent Incomes, and Income Dynamics: Comparing Europe to the United States," Work and Occupations, 2005, 32, 140 -162.

Gottschalk, Peter and Robert Moffitt, "The Growth of Earnings Instability in the U.S. Labor Market," Brookings Papers on Economic Activity, 1994, 25 (1994-2), 217-272.

Heckman, James J. and Carmen Pages, "The Cost of Job Security Regulation: Evidence from Latin American Labor Markets," NBER Working Papers 7773, National Bureau of Economic Research, Inc June 2000.

Huneeus, Cristóbal and Andrea Repetto, "The Dynamics of Earnings in Chile," in Jorge Restrepo, Andrea Tokman R., Norman Loayza (Series Editor), and Klaus SchmidtHebbel (Series Edi, eds., Labor Markets and Institutions, Vol. 8 of Central Banking, Analysis, and Economic Policies Book Series, Central Bank of Chile, 02 2005, chapter 12, pp. 383-410.

Jenkins, Stephen P. and Philippe Van Kerm, "The Measurement of Economic Inequality," in "The Oxford Handbook of Economic Inequality," Oxford University Press, 2011.

Krueger, Dirk and Fabrizio Perri, "Does Income Inequality Lead to Consumption Inequality? Evidence and Theory," Review of Economic Studies, 01 2006, 73 (1), 163-193.

Larrañaga, Osvaldo, "Inequality, Poverty and Social Policy: Recent Trends in Chile," OECD Social, Employment and Migration Working Papers 85, OECD Publishing April 2009.

Lilla, Marco and Stefano Staffolani, "The evolution of wage inequality in Italy," Applied Economics, 2009, 41 (15), 1873-1892.

Low, Hamish, Costas Meghir, and Luigi Pistaferri, “Wage Risk and Employment Risk over the Life Cycle," American Economic Review, September 2010, 100 (4), 1432-67.

Moffitt, Robert A. and Peter Gottschalk, "Trends in the Transitory Variance of Earnings in the United States," Economic Journal, March 2002, 112 (478), C68-C73.

Postel-Vinay, Fabien and Hélène Turon, "On-The-Job Search, Productivity Shocks, And 
The Individual Earnings Process," International Economic Review, 08 2010, 51 (3), 599-629.

Ridder, Geert and Gerard J. van den Berg, "Measuring Labor Market Frictions: A CrossCountry Comparison," Journal of the European Economic Association, 03 2003, 1 (1), 224-244. Sapelli, Claudio, Chile Más Equitativo? Una Mirada Distinta a la Distribución del Ingreso, la Movilidad Social y la Pobreza en Chile, Ediciones UC, 2011.

Subsecretaría de Previsión Social, "Social Protection Survey," available in www.proteccionsocial.cl, 2002.

van den Berg, Gerard J. and Geert Ridder, "An Empirical Equilibrium Search Model of the Labor Market," Econometrica, September 1998, 66 (5), 1183-1222.

Wolpin, Kenneth I, "Estimating a Structural Search Model: The Transition from School to Work," Econometrica, July 1987, 55 (4), 801-17. 
TABle 1. Descriptive Statistics on Durations (Months)

\begin{tabular}{lcccccc}
\hline \hline \multirow{2}{*}{ Event } & \multicolumn{3}{c}{ Skilled } & \multicolumn{3}{c}{ Unskilled } \\
& Mean & S.D. $\%$ of RC & Mean & S.D. & \% of RC \\
\hline \multicolumn{7}{c}{ All Cycles } \\
\hline$t_{u}$ & 10.72 & 22.54 & 0.04 & 8.33 & 20.99 & 0.06 \\
$t_{1}$ & 114.84 & 73.91 & 0.67 & 100.41 & 78.61 & 0.55 \\
$t_{2}$ & 18.01 & 13.22 & 0.12 & 15.62 & 12.14 & 0.12 \\
\hline \multicolumn{7}{c}{ Cycles Starting in Unemployment State } \\
\hline$t_{u}$ & 10.72 & 22.54 & 0.27 & 8.33 & 20.99 & 0.23 \\
$t_{1}$ & 12.22 & 13.42 & 0.35 & 9.65 & 11.26 & 0.29 \\
$t_{2}$ & 12.63 & 8.78 & 0.13 & 12.41 & 11.18 & 0.09 \\
\hline \multicolumn{7}{c}{ Cycles Starting in Employment State } \\
\hline$t_{1}$ & 127.88 & 68.00 & 0.73 & 127.45 & 69.25 & 0.65 \\
$t_{2}$ & 19.05 & 13.70 & 0.12 & 16.70 & 12.27 & 0.13 \\
\hline \hline
\end{tabular}

Note: Left censored spells are as much as $0.6 \%$ and $1.6 \%$ of the total spells for skilled and unskilled workers, respectively.

TABLE 2. Descriptive Statistics on Wages (U.S. Dollars of 2004)

\begin{tabular}{|c|c|c|c|c|c|c|}
\hline \multirow[t]{2}{*}{ Event } & \multicolumn{3}{|c|}{ Skilled } & \multicolumn{3}{|c|}{ Unskilled } \\
\hline & Mean & S.D. & $\% w_{t+1}>w_{t}$ & Mean & S.D. & $\% w_{t+1}>w_{t}$ \\
\hline \multicolumn{7}{|c|}{ All Cycles } \\
\hline$w_{u} / w_{1}$ & 5.18 & 3.77 & 0.85 & 1.94 & 0.94 & 0.82 \\
\hline$w_{2}$ & 4.21 & 2.95 & 0.16 & 1.73 & 0.75 & 0.18 \\
\hline$w_{3}$ & 4.38 & 2.90 & & 1.81 & 0.86 & \\
\hline \multicolumn{7}{|c|}{ Cycles Starting in Unemployment State } \\
\hline$w_{u}$ & 3.34 & 2.89 & 0.66 & 1.45 & 0.60 & 0.69 \\
\hline$w_{2}$ & 4.17 & 2.72 & 0.18 & 1.54 & 0.54 & 0.17 \\
\hline$w_{3}$ & 6.08 & 4.02 & & 1.65 & 0.70 & \\
\hline \multicolumn{7}{|c|}{ Cycles Starting in Employment State } \\
\hline$w_{1}$ & 5.42 & 3.80 & 0.89 & 2.08 & 0.98 & 0.87 \\
\hline$w_{2}$ & 4.22 & 3.00 & 0.16 & 1.80 & 0.79 & 0.18 \\
\hline$w_{3}$ & 4.04 & 2.55 & & 1.87 & 0.90 & \\
\hline
\end{tabular}

Notes: The figures, expressed in U.S. dollars of 2004, were calculated using the 2004 average exchange rate: 609.55 Pesos/US. 
TABLE 3. Maximun Likelihood Estimates

\begin{tabular}{lccc}
\hline \hline Parameter & All Workers & Skilled Workers & Unskilled Workers \\
\hline$\lambda_{U}$ & 0.08896 & 0.06800 & 0.09279 \\
& $(0.00355)$ & $(0.00707)$ & $(0.00195)$ \\
$\lambda_{E}$ & 0.00923 & 0.01170 & 0.00717 \\
& $(0.00044)$ & $(0.00078)$ & $(0.00032)$ \\
$\lambda_{R}$ & 0.00000 & 0.00000 & 0.00000 \\
& $(0.00000)$ & $(0.00000)$ & $(0.00000)$ \\
$\eta$ & 0.00169 & 0.00085 & 0.00195 \\
& $(0.00007)$ & $(0.00009)$ & $(0.00015)$ \\
$\mu$ & 0.79049 & 1.53089 & 0.54656 \\
& $(0.01837)$ & $(0.06597)$ & $(0.02602)$ \\
$\sigma$ & 0.20829 & 0.09220 & 0.26476 \\
& $(0.00633)$ & $(0.01197)$ & $(0.01284)$ \\
$w^{*}$ & 1.13852 & 3.46890 & 0.67888 \\
& $(0.03785)$ & $(0.25994)$ & $(0.02812)$ \\
$\mu_{\epsilon}$ & -0.24523 & -0.30472 & -0.13222 \\
& $(0.01039)$ & $(0.03188)$ & $(0.00697)$ \\
\hline$b$ & -0.0672 & 2.58990 & -0.63440 \\
$E(w)$ & 2.25282 & 4.64196 & 1.78891 \\
$V(w)$ & 0.22503 & 0.18395 & 0.23238 \\
\hline $\log L$ & -14993 & -2670 & -12066 \\
$N$ & 3265 & 693 & 2572 \\
\hline \hline
\end{tabular}

Note: Asymptotic standard errors in parentheses. 
TABLE 4. Lifetime vs Cross-Section Inequality Measures

\begin{tabular}{|c|c|c|c|c|c|}
\hline & $n_{s} / n$ & $y$ & $G E(0)$ & $G E(1)$ & $G E(2)$ \\
\hline \multicolumn{6}{|c|}{ Lifetime Inequality Measures: Welfare } \\
\hline Total & 1.0000 & 25.4951 & 0.2716 & 0.2269 & 0.2508 \\
\hline Skilled & 0.2125 & 34.9116 & 0.3006 & 0.1925 & 0.1683 \\
\hline Unskilled & 0.7876 & 16.0787 & 0.1908 & 0.1452 & 0.1370 \\
\hline Within-group Inequality & & & 0.2141 & 0.1627 & 0.1773 \\
\hline Between-group Inequality & & & 0.0575 & 0.0642 & 0.0736 \\
\hline \multicolumn{6}{|c|}{ Cross-Section Inequality Measures: Simulated Earnings } \\
\hline Total & 1.0000 & 3.3818 & 0.2866 & 0.3180 & 0.5102 \\
\hline Skilled & 0.2138 & 4.8289 & 0.3085 & 0.3065 & 0.4078 \\
\hline Unskilled & 0.7862 & 1.9348 & 0.1765 & 0.1709 & 0.2004 \\
\hline Within-group Inequality & & & 0.2047 & 0.2257 & 0.4022 \\
\hline Between-group Inequality & & & 0.0819 & 0.0923 & 0.1080 \\
\hline \multicolumn{6}{|c|}{ Cross Section Inequality Measures: Observed Earnings } \\
\hline Total & 1.0000 & 3.6826 & 0.2253 & 0.2598 & 0.3741 \\
\hline Skilled & 0.2410 & 5.3095 & 0.2308 & 0.2219 & 0.2494 \\
\hline Unskilled & 0.7590 & 2.0558 & 0.0991 & 0.1009 & 0.1105 \\
\hline Within-group Inequality & & & 0.1308 & 0.1554 & 0.2540 \\
\hline Between-group Inequality & & & 0.0944 & 0.1044 & 0.1201 \\
\hline
\end{tabular}

Note: Observed earnings correspond to those observed in June 2004. Simulated earnings are corrected for measurement error to make them comparable with the observed earnings. Lifetime inequality measures are calculated using the true earnings, and therefore do not include the measurement error. 
TABLE 5. Lifetime Inequality Measures Decomposition

\begin{tabular}{lcccccc}
\hline \hline & \multicolumn{3}{c}{ Index - Mobility } & \multicolumn{3}{c}{ Index - Distribution } \\
& $G E(0)$ & $G E(1)$ & $G E(2)$ & $G E(0)$ & $G E(1)$ & $G E(2)$ \\
\hline Total & 0.1079 & 0.1118 & 0.1261 & 0.2764 & 0.2038 & 0.20373 \\
Skilled & 0.0374 & 0.0323 & 0.0293 & 0.3931 & 0.2507 & 0.23974 \\
Unskilled & 0.0415 & 0.0388 & 0.0381 & 0.2431 & 0.1875 & 0.18835 \\
Within-group Inequality & 0.0406 & 0.0363 & 0.0387 & 0.2749 & 0.2023 & 0.20224 \\
Between-group Inequality & 0.0673 & 0.0755 & 0.0874 & 0.0014 & 0.0015 & 0.00149 \\
\hline & $\%$ Explained - Mobility & \% Explained - Distribution \\
\hline Total & 0.7594 & 0.6641 & 0.6370 & -0.0219 & 0.1334 & 0.2405 \\
Skilled & 1.1019 & 1.1778 & 1.2401 & -0.3871 & -0.4278 & -0.6374 \\
Unskilled & 1.0660 & 1.1011 & 1.1308 & -0.3733 & -0.4367 & -0.5877 \\
Within-group Inequality & 1.0774 & 1.1266 & 1.1043 & -0.3775 & -0.3529 & -0.1991 \\
Between-group Inequality & -0.1804 & -0.1857 & -0.1964 & 1.0290 & 1.0270 & 1.0246 \\
\hline \hline
\end{tabular}


Figure 1. Cross-Section Inequality and Labor Market Structure

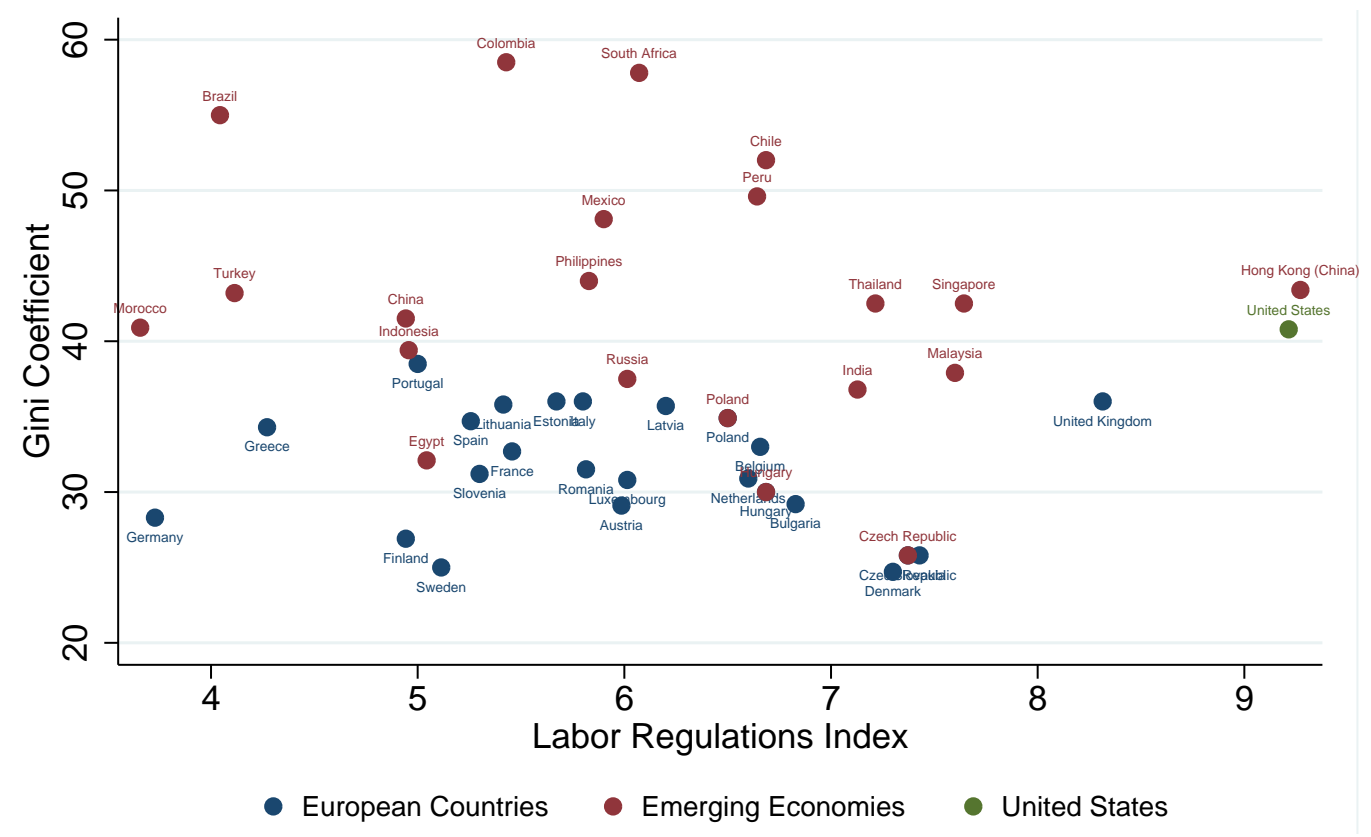

Sources: WDI World Bank 1997-2009, IEF Economic Freedom Annual Report 2002-2008 
FIGURE 2. Contributions to the Inequality Index of Market Income - Working age population in the late $2000 \mathrm{~s}$

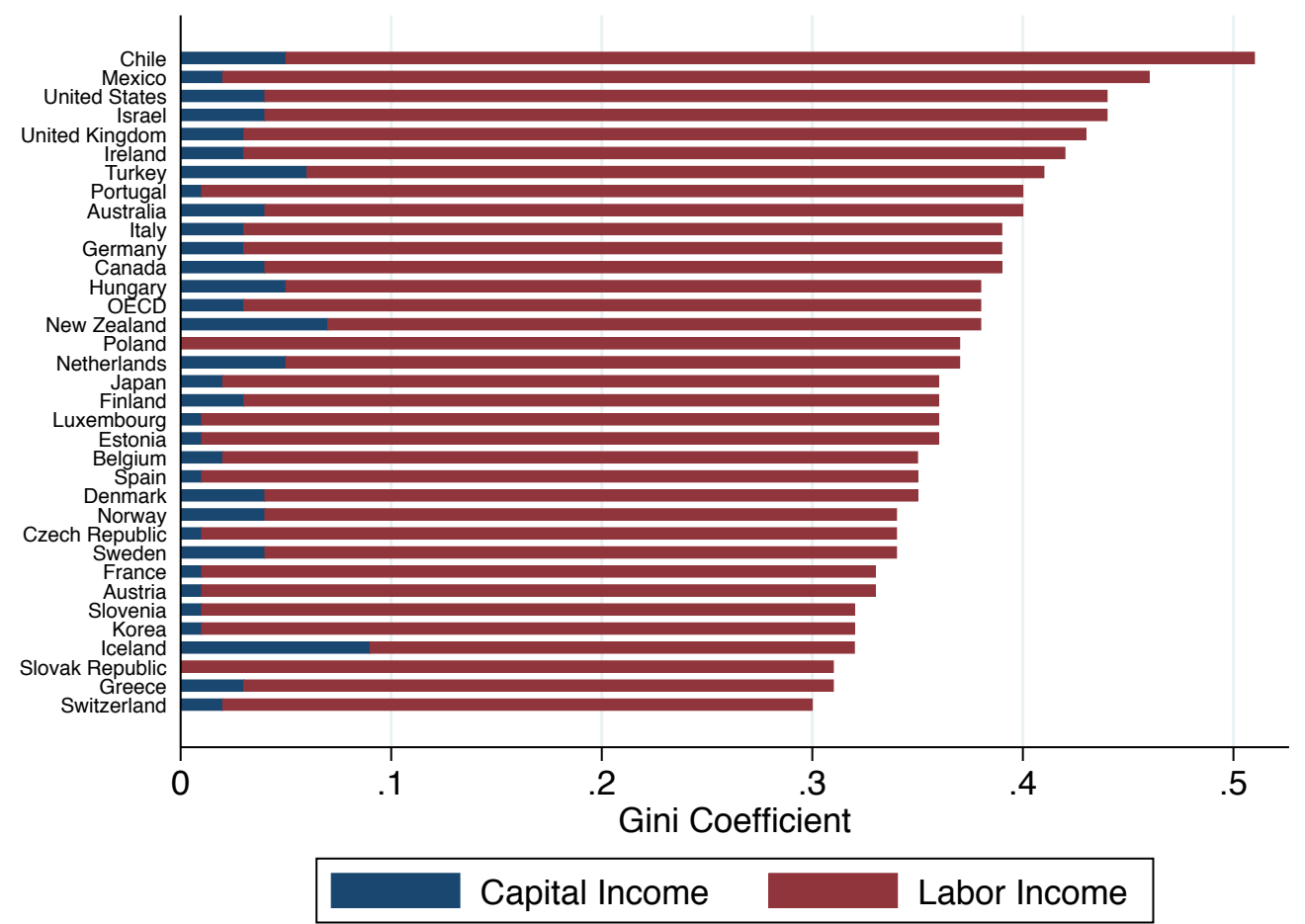

Note: Contributions to overall household market income inequality are derived by multiplying the concentration coefficients of each income source by their weight in total market income. The data for Greece, Hungary, Mexico and Turkey are net of taxes. Data for France and Ireland refer to the mid-2000s.

Source: OECD Income Distribution and Poverty, OECD Social Expenditure Statistics (database). Borrowed from OECD's Economic Policy Reforms: Going for Growth 2012. 
FIgURE 3. Example of an Individual Labor Market History that becomes Two Cycles
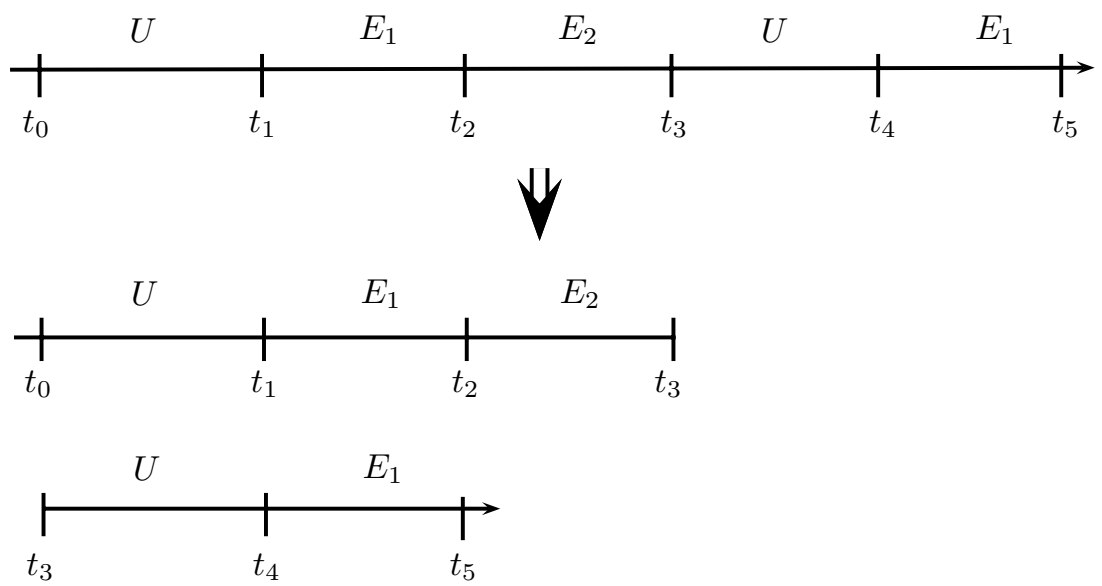
FIGURE 4. Effect of Individual Parameters on Lifetime Inequality Measures Skilled Workers
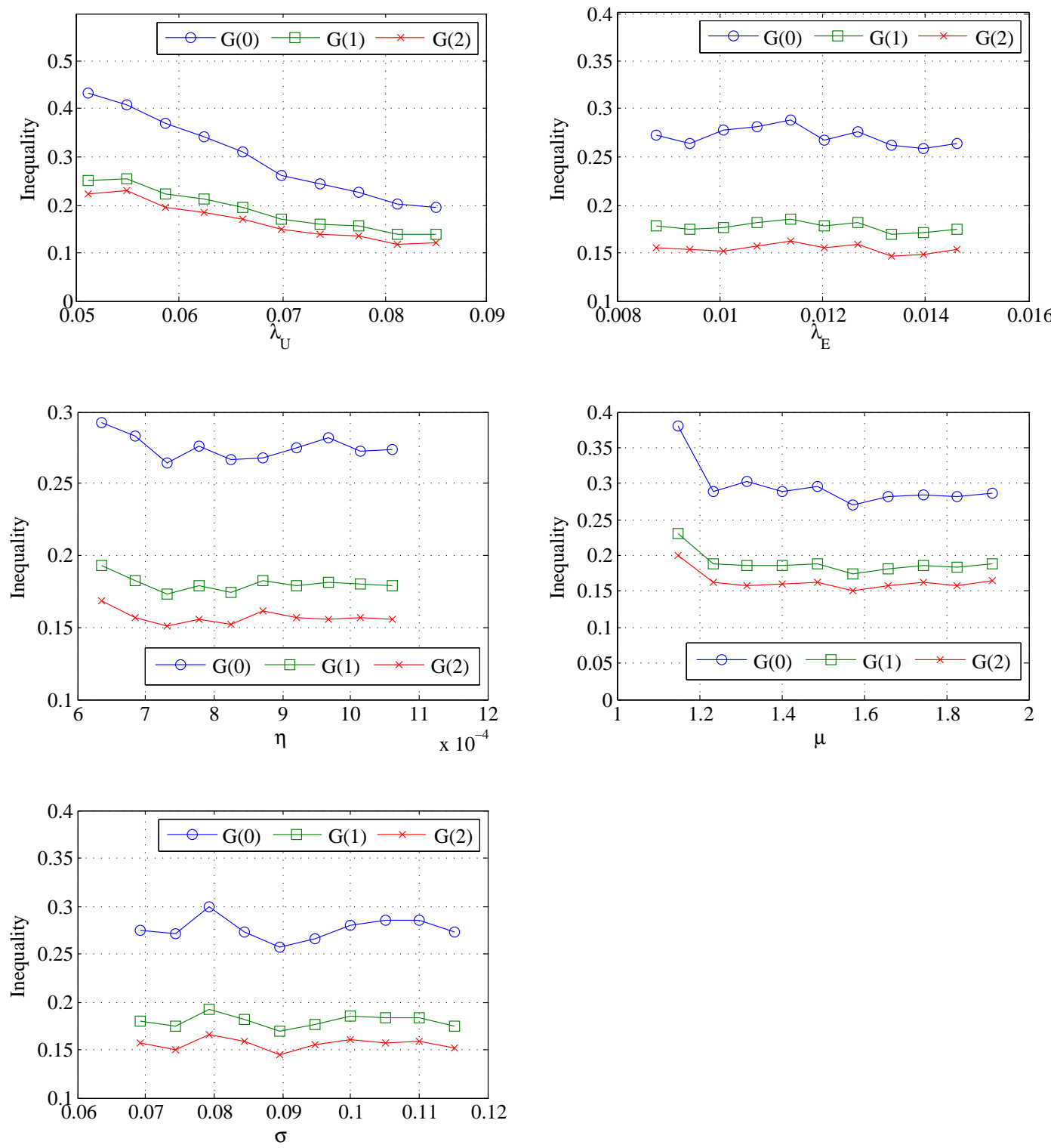

Note: Calculations based on simulations of 2,123 individuals, while changing each parameter at a time and maintaining the remaining parameters in their estimated values. All the equilibrium effects are taken into account in each simulation. 
FIGURE 5. Effect of Individual Parameters on Lifetime Inequality Measures Unskilled Workers
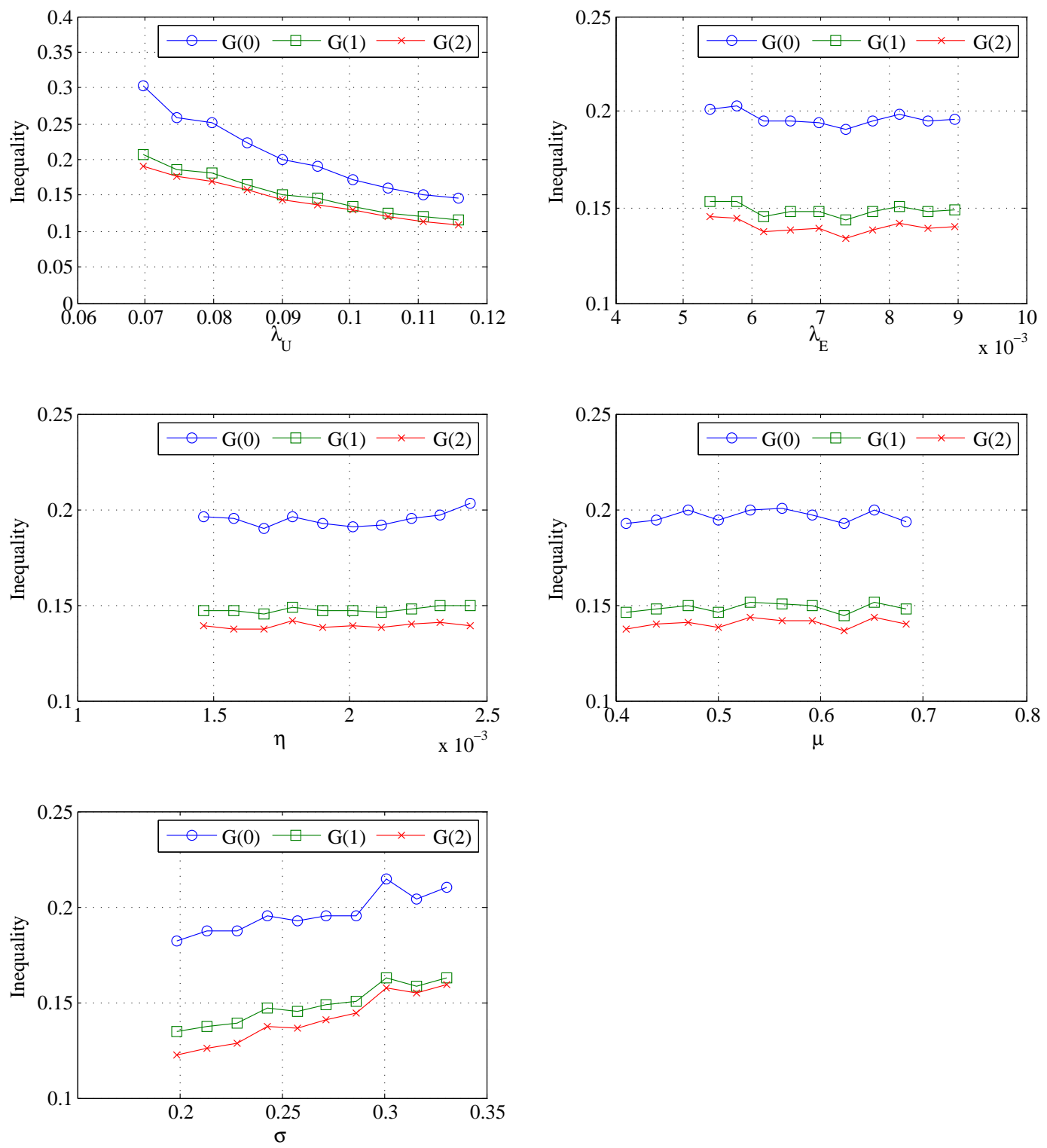

Note: Calculations based on simulations of 7,877 individuals, while changing each parameter at a time and maintaining the remaining parameters in their estimated values. All the equilibrium effects are taken into account in each simulation. 
FIGURE 6. Mobility Parameters by Age - Skilled Workers
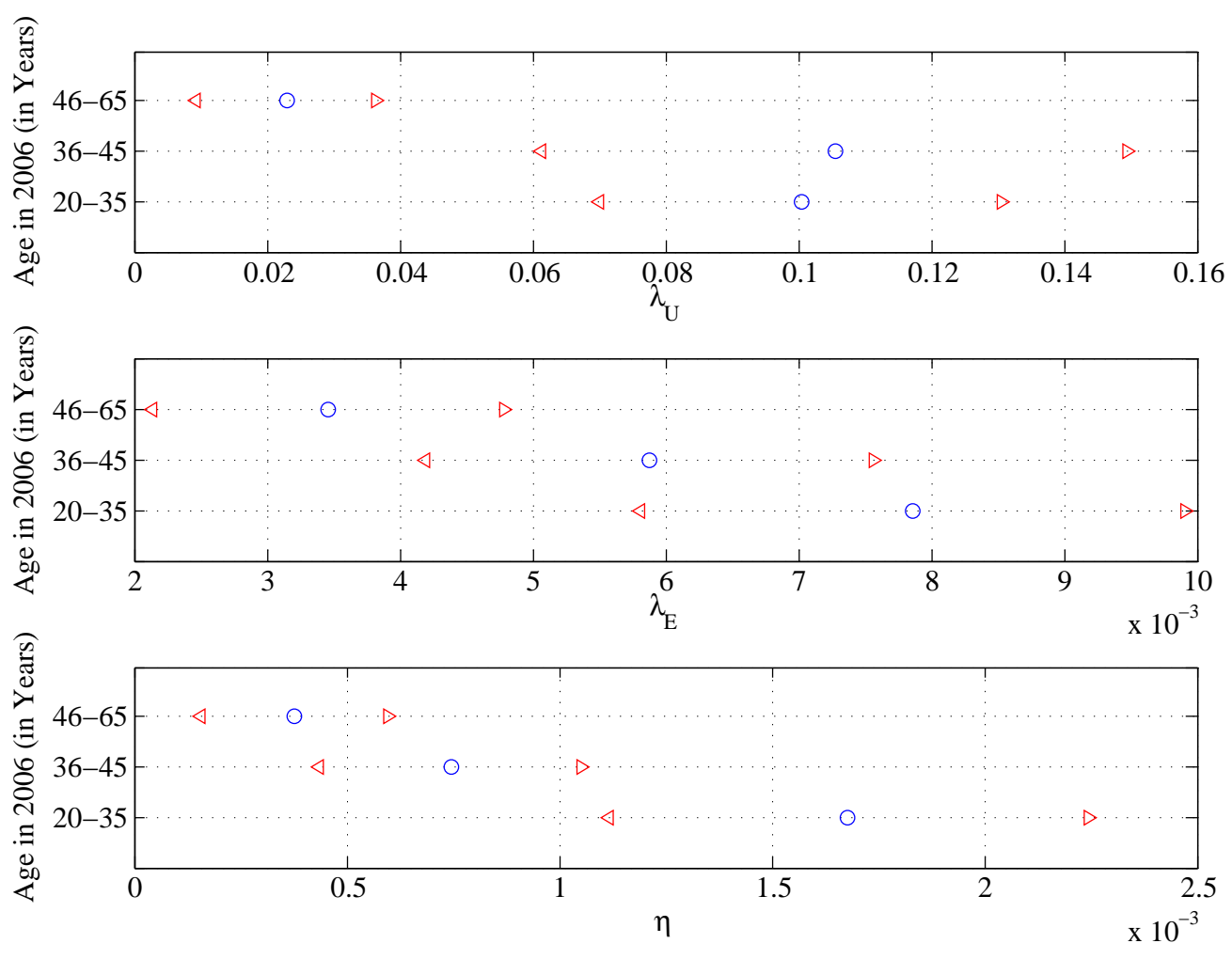

Note: $\circ$ represents the estimated parameter and $\triangleleft$ and $\triangleright$ a $95 \%$ confidence interval. 
FIGURE 7. Mobility Parameters by Age - Unskilled Workers
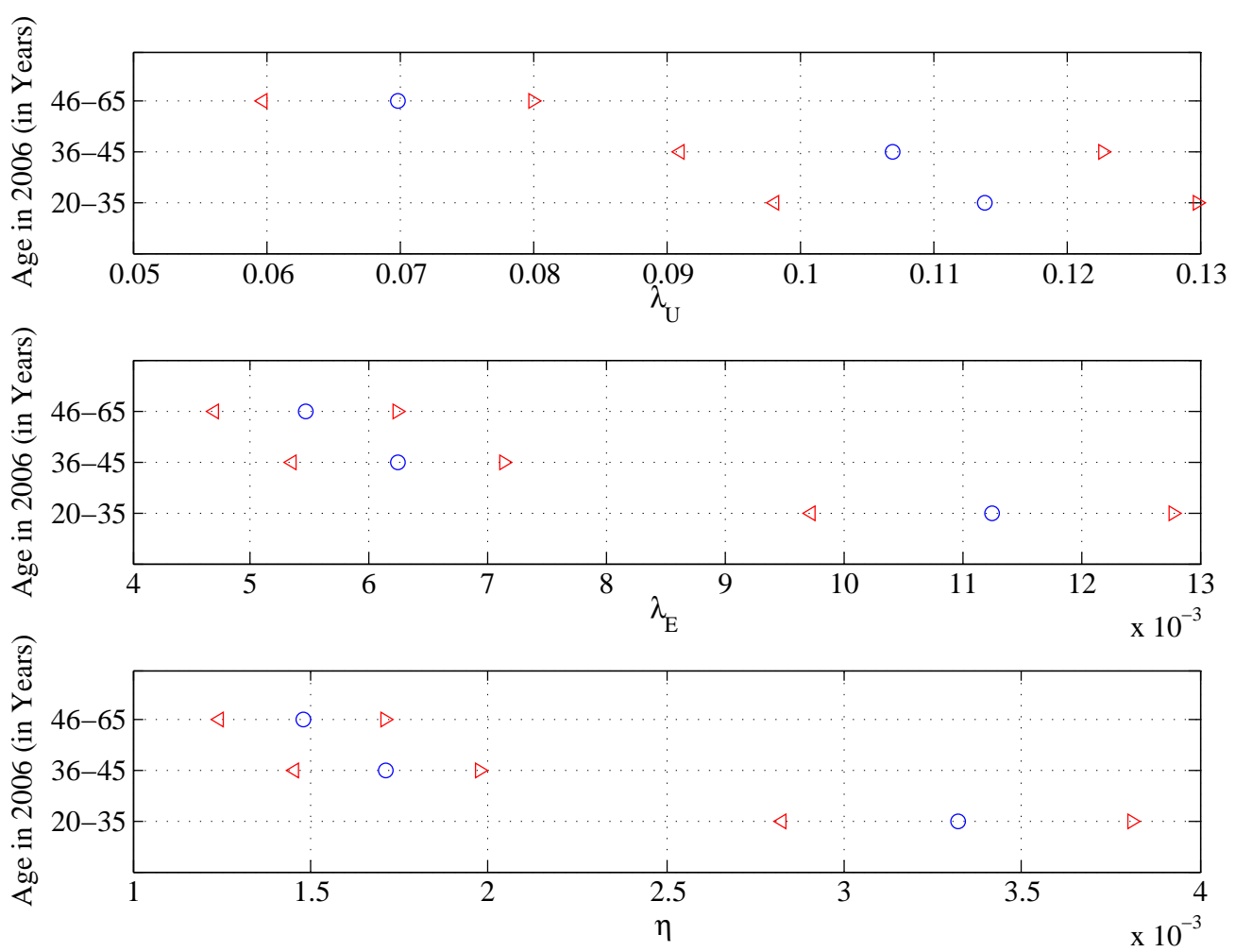

Note: $\circ$ represents the estimated parameter and $\triangleleft$ and $\triangleright$ a $95 \%$ confidence interval. 